\title{
Rainfall intensity-duration thresholds for bedload transport initiation in small Alpine watersheds
}

\author{
A. Badoux ${ }^{1}$, J. M. Turowski ${ }^{1}$, L. Mao ${ }^{2}$, N. Mathys ${ }^{3}$, and D. Rickenmann ${ }^{1}$ \\ ${ }^{1}$ Swiss Federal Research Institute WSL, Zürcherstrasse 111, 8903 Birmensdorf, Switzerland \\ ${ }^{2}$ Pontificia Universidad Católica de Chile, Department of Ecosystems and Environment, Av. Vicuña Mackenna 4860, Macul, \\ Santiago, Chile \\ ${ }^{3}$ Irstea, ETGR Research Unit, BP 76, 38402 Saint Martin d'Hères, France
}

Correspondence to: A. Badoux (badoux@wsl.ch)

Received: 20 January 2012 - Revised: 22 August 2012 - Accepted: 30 August 2012 - Published: 18 October 2012

\begin{abstract}
Although channel discharge represents one of the primary controls of bedload transport rates in mountain streams, it is rarely measured in small, steep catchments. Thus, it is often impossible to use it as a predictor of hazardous bedload events. In this study, the characteristics of rainfall events leading to bedload transport were investigated in five small Alpine catchments located in different geographical and morphological regions of Switzerland, Italy and France. Using rainfall data at high temporal resolution, a total of 370 rainfall events were identified that led to abundant sediment transport in the different catchments, and corresponding threshold lines were defined using a power law in intensity-duration space. Even though considerable differences in the distribution of the rainfall data were identified between catchments located in various regions, the determined threshold lines show rather similar characteristics.

Such threshold lines indicate critical conditions for bedload transport initiation, but rainfall events that do not cause transport activity (so called no-bedload events) can still plot above them. With 0.67 overall in the Erlenbach (Swiss Prealps) and 0.90 for long-duration, low-intensity rainfall, the false alarm rate is considerable. However, for short-duration, high-intensity events, it is substantially smaller (0.33) and comparable to values determined in previous studies on the triggering of Alpine debris flows. Our results support the applicability of a traditional, generalized threshold for prediction or warning purposes during high-intensity rainfall. Such (often convective) rainfall events are unfortunately (i) difficult to measure, even by dense rain gauge networks, and (ii) difficult to accurately predict, both due to their small spatial and temporal scales. Still, for the protection of human
\end{abstract}

life (e.g. along transportation infrastructure such as roads and railway) automated alerts based on power law threshold lines may be useful.

\section{Introduction}

Bedload transport represents a principal natural hazard in mountainous regions (e.g. Rickenmann and Koschni, 2010). Sediment deposition on alluvial fans occurring as a result of a rapid decrease in channel gradient regularly leads to overbank flooding along critical reaches during large flood events. Therefore, wherever mountain streams affect Alpine communities, bedload transport has to be considered in hazard mapping and evaluation (e.g. Holub and Hübl, 2008). During the large storm events of 2005 in Switzerland (Bezzola and Hegg, 2007), an estimated one third to one half of the total damage, at a cost of three billion Swiss francs, was associated with sediment transport processes (Nitsche et al., 2011), based on data from the Swiss flood and landslide damage database (Hilker et al., 2009). In most of the widely used bedload equations, the incipient motion of individual sediment particles (and thus the occurrence of bedload transport in a stream) is described by a critical discharge or shear stress. Such threshold values are determined by both the local hydrodynamic conditions, the nature of the particle (e.g. its size, shape, weight, etc.), and its immediate surroundings (e.g. Buffington and Montgomery, 1997; Turowski et al., 2011). These factors are difficult to assess, to measure and to monitor, and thus the onset of bedload transport and 
the accurate prediction of transport rates have proved to be notoriously difficult.

Channel discharge is the primary control of sediment entrainment and transport rates in mountain streams. However, discharge is rarely measured in small catchments, and thus it is often impossible to use it as a predictor of hazardous sediment events in mountain communities. With the steady development of precipitation measurement networks in Alpine regions and the progress accomplished in radar precipitation estimation over the last decades, rainfall lends itself as a means for warning purposes in sediment transport prone areas.

The water input into a river basin or hillslope (rainfall conditions and/or snowmelt) has been shown to strongly influence the initiation of debris flows and other instability phenomena. Often, triggering conditions are described by the definition of empirical thresholds showing the relation between rain storm characteristics, prevalently duration and average rainfall intensity. As a matter of fact, such relationships have been investigated and demonstrated in a multitude of studies throughout the world. Guzzetti et al. (2008) gave an updated overview on the rainfall intensity-duration (ID) control of shallow landslides and debris flows. They compiled a very extensive global database of rainfall events that triggered shallow landslides and debris flows through a literature search and established a new global ID threshold for these processes. Furthermore, the effect of climate on the initiation of shallow landslides and debris flows was investigated by assessing thresholds for different climatic regions. Case studies on debris-flow initiation in the European Alps include Gregoretti and Dalla Fontana (2007, 2008), Berti and Simoni (2005), Deganutti et al. (2000), Blijenberg (1998), Zimmermann et al. (1997), and Ceriani et al. (1992). Diakakis (2012) showed that ID threshold lines are good predictors for the occurrence of floods in mediumsized Mediterranean catchments.

By combining empirical rainfall thresholds for mass movement activity with forecasts and real-time measurements of precipitation, it is possible to issue early warnings for instabilities of any kind. Such a concept was realized by the US Geological Survey and the National Oceanic and Atmospheric Administration's National Weather Service (Keefer et al., 1987). A debris-flow prediction and warning system was operated from 1986 to 1995 and provided early warning times of several hours before threshold exceedance. Similarly, a completely automated system for shallow landslide forecasting is used in Hong Kong (Chan and Pun, 2004).

Comparable efforts for the prediction of severe fluvial bedload transport events in mountain streams are not known to the authors. The establishment of empirical intensityduration thresholds requires continuous information on the occurrence and magnitude of sediment transport in a water course. However, such datasets are still scarce. In this study, we investigate rainfall thresholds for bedload transport ac-

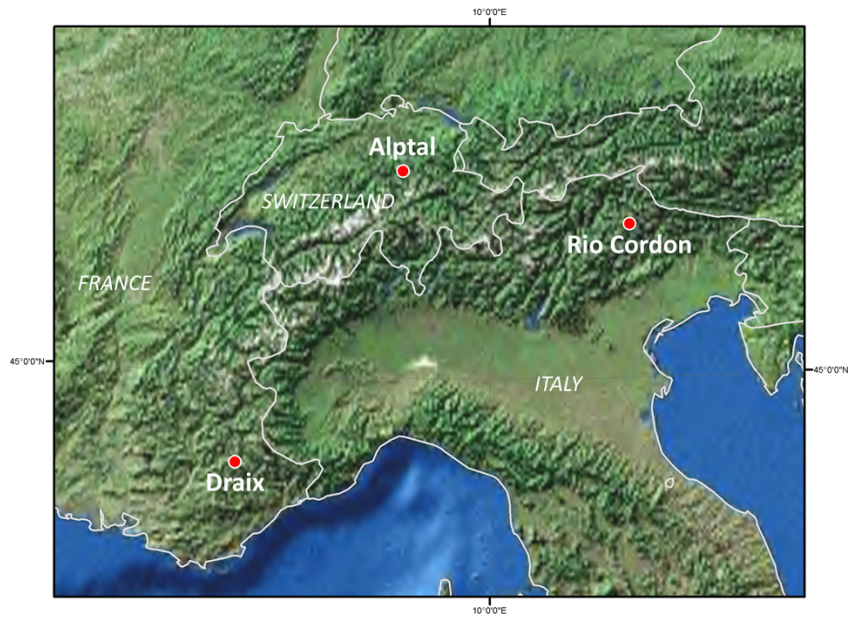

Fig. 1. Location of the three experimental sites: Alptal (Swiss Prealps), Rio Cordon (Eastern Italian Alps) and Draix (Southern French Alps).

tivity in five Alpine experimental catchments (Fig. 1; Table 1) considering storm duration and rainfall intensity. Furthermore, we compare our results with threshold lines for other natural hazard processes such as debris flows and shallow landslides. Finally, the practicability of our approach for early warning purposes along mountain streams prone to hazardous bedload transport is discussed.

\section{Data and methods}

\subsection{Erlenbach and Vogelbach catchments (Alptal experimental site, Switzerland)}

\subsubsection{Experimental research site}

The Vogelbach and Erlenbach are small experimental headwater catchments in the Swiss Prealps where hydrological research has been carried out for the last $35 \mathrm{yr}$ (Hegg et al., 2006; Fig. 1). The two streams are located on opposite sides of the upper Alptal valley, which is characterized by flysch geology. They flow into the Alp River at the Alptal valley bottom and drain areas of $1.56 \mathrm{~km}^{2}$ and $0.70 \mathrm{~km}^{2}$, respectively. The research catchments have been previously described by Hegg et al. (2006), Rickenmann and McArdell (2007), and Turowski et al. (2009), and the basic catchment characteristics are summarized in Table 1.

Streamflow and hydrometeorological data have been continuously monitored by the Swiss Federal Research Institute WSL since 1975 (Vogelbach) and 1978 (Erlenbach). Furthermore, bedload data is monitored in both streams, although the Vogelbach dataset is much shorter and of lesser quality than the Erlenbach dataset.

In the Erlenbach, a sediment retention basin was built in 1982 to acquire information on annual sediment loads. 
Table 1. Characteristics of the five experimental catchments (cf. Fig. 1).

\begin{tabular}{|c|c|c|c|c|c|}
\hline $\begin{array}{l}\text { Catchment } \\
\text { characteristic }\end{array}$ & $\begin{array}{r}\text { Erlenbach } \\
\text { (Alptal) }\end{array}$ & $\begin{array}{r}\text { Vogelbach } \\
\text { (Alptal) }\end{array}$ & Rio Cordon & $\begin{array}{r}\text { Laval } \\
\text { (Draix) }\end{array}$ & $\begin{array}{r}\text { Moulin } \\
\text { (Draix) }\end{array}$ \\
\hline Catchment exposition & $\mathrm{W}$ & ESE & $S$ & $\mathrm{~W}$ & SW \\
\hline Catchment area $\left(\mathrm{km}^{2}\right)$ & 0.70 & 1.55 & 5.0 & 0.86 & 0.09 \\
\hline Elevation range above sea level (m) & $1110-1655$ & $1050-1545$ & $1763-2748$ & $850-1250$ & 850-925 \\
\hline Average gradient of main stream & 0.18 & 0.17 & 0.14 & $0.04-0.08^{\mathrm{a}}$ & $0.04-0.08^{\mathrm{a}}$ \\
\hline Characteristic grain size $d_{50}(\mathrm{~mm})$ & 80 & 60 & 119 & $2-8$ & $1.5-5$ \\
\hline Characteristic grain size $d_{90}(\mathrm{~mm})$ & 300 & 480 & 451 & $8-37$ & $5-33$ \\
\hline Observed/estimated critical discharge $Q_{\mathrm{c}}\left(\mathrm{m}^{3} \mathrm{~s}^{-1}\right)$ & $0.49^{\mathrm{b}}$ & $0.69^{\mathrm{c}}$ & $1.80^{\mathrm{d}}$ & $0.10^{\mathrm{e}}$ & $0.05^{\mathrm{e}}$ \\
\hline Mean annual precipitation $(\mathrm{mm})$ & 2290 & 2160 & 1100 & 920 & 920 \\
\hline Fraction of forest/scrub cover & 0.39 & 0.63 & 0.25 & 0.32 & 0.46 \\
\hline Fraction of wetland and grassland & 0.61 & 0.37 & 0.61 & - & - \\
\hline Fraction of unvegetated land & $\ll 0.01$ & $\ll 0.01$ & 0.14 & 0.68 & 0.54 \\
\hline
\end{tabular}

${ }^{\mathrm{a}}$ Laval: $\sim 1000 \mathrm{~m}$ long main channel; Moulin: $\sim 300 \mathrm{~m}$ long main channel (Mathys, 2006). ${ }^{\mathrm{b}}$ From Turowski et al. (2011). ${ }^{\mathrm{c}}$ Estimated using the formula proposed by Bathurst et al. (1987) and adapted by Rickenmann (1990). ${ }^{\mathrm{d}}$ Based on Fig. 2 in Lenzi et al. (2006), for mean grain size of $0.12 \mathrm{~m}$ and mean channel width of $6 \mathrm{~m}$. e Estimated using smallest known transport events.

Indirect bedload sensors were installed just above the retention basin in 1986 to monitor transport rates at a higher temporal resolution. The first generation of sensors was known as piezoelectric bedload impact sensors (PBIS) whose core, a piezoelectric crystal, generates a small electrical potential when it is deformed (Rickenmann and McArdell, 2007). The sensors were fixed under steel plates that are mounted flush with the bed in a check dam across the flow. Vibrations caused by grains passing the plates are detected by the sensor. This signal is subsequently amplified, processed, and so-called "impulses" - the number of peaks above a defined threshold - are registered (Turowski and Rickenmann, 2009; Rickenmann and McArdell, 2007). In 1999 the PBI sensors in the Erlenbach were replaced by commercial geophones. Geophone sensors have two main advantages over PBI sensors: they are commercially available and thus less expensive, and they produce a more standardized signal response (Rickenmann and Fritschi, 2010; Turowski et al., 2009). Furthermore, they are expected to be more reliable and to have a longer life time than the formerly used PBI sensors. A similar setup also using geophone sensors was installed at the neighbouring Vogelbach in 2002. An overview over the sediment transport measurements in the Alptal experimental site is given in Table 2.

\subsubsection{Sediment transport data}

The impulses recorded by the indirect bedload sensors at the Erlenbach are summed up for a certain time period (typically around one year) and put into relation to the total volume of sediment deposited and subsequently surveyed in the retention basin. The total volume is fractioned according to the impulse sums of the different bedload transport events. This calibration method allows for an estimation of event volumes within a factor of about two (Rickenmann and McArdell, 2008; Rickenmann et al., 2012). The Vogelbach is not equipped with a retention basin and the direct calibration of the sensors is thus not possible. Therefore, the estimation of sediment volumes for the Vogelbach is based on calibration measurements of the geophone system in five mountain streams in the Austrian and Swiss Alps (including the Erlenbach) (unpublished data, 2012).

For the Erlenbach, we have determined a threshold value for event volume and split the dataset in two parts: (i) large bedload transport events and (ii) small bedload transport events. In small bedload transport events, transport was recorded with the geophone sensors, but the estimated total transported bedload volume was less than $1 \mathrm{~m}^{3}$. The movement of single gravel particles along the channel during minor floods fits into this category. This is an arbitrary approach, but various sources of uncertainty require such a procedure. Small events represent the transition to the so-called no-bedload events which are simply rainfall periods that did not cause enough discharge in the stream to generate any detectable bedload transport. The distinction of small and nobedload events was carried out for the Erlenbach only. In the Vogelbach such a division was not undertaken because of the impossibility of direct calibration. All event types for the study catchments are summarized in Table 3. Peak flows and bedload volumes for large transport events range from 0.3 to $10.1 \mathrm{~m}^{3} \mathrm{~s}^{-1}$ (10-min data) and 1.0 to $1540 \mathrm{~m}^{3}$, respectively. Of course, not all large bedload events would represent a hazard in a catchment without a retention basin but otherwise comparable to the Erlenbach. Actually, only about 20 to 30 events in the dataset delivered a sediment volume large enough to potentially endanger, for example, traffic infrastructure such as roads or bridges.

Bedload events in the Erlenbach and Vogelbach that occurred during winter months were omitted because the main target of the study is the description of rainfall episodes initiating bedload transport in mountain streams. Thus, we 
Table 2. Data acquisition at the different experimental sites.

\begin{tabular}{|c|c|c|c|c|}
\hline Variable & Erlenbach (Alptal) & Vogelbach (Alptal) & Rio Cordon & $\begin{array}{l}\text { Laval and Moulin } \\
\text { (Draix) }\end{array}$ \\
\hline Sediment transport rate & $\begin{array}{l}\text { 1-min interval } \\
\text { (geophones) }\end{array}$ & $\begin{array}{l}\text { 1-minute interval } \\
\text { (geophones) }\end{array}$ & $\begin{array}{l}\text { 5-min interval } \\
\text { (ultrasonic sensors) }^{\mathrm{a}, \mathrm{b}}\end{array}$ & no measurement \\
\hline Begin and end of motion & $\begin{array}{l}\text { 1-min interval } \\
\text { (geophones) }\end{array}$ & $\begin{array}{l}\text { 1-min interval } \\
\text { (geophones) }\end{array}$ & $\begin{array}{l}\text { 5-min interval }{ }^{\mathrm{a}} \\
\text { (ultrasonic sensors) }\end{array}$ & no measurement \\
\hline Sediment transport volume & $\begin{array}{l}\text { annual survey of reten- } \\
\text { tion basin }\end{array}$ & no measurement & $\begin{array}{l}\text { post-event topographi- } \\
\text { cal survey of retention } \\
\text { basin }\end{array}$ & $\begin{array}{l}\text { periodic survey of sedi- } \\
\text { ment traps }{ }^{c}\end{array}$ \\
\hline Rainfall & $\begin{array}{l}\text { 10-min interval } \\
\text { (tipping bucket) }\end{array}$ & $\begin{array}{l}\text { 10-min interval } \\
\text { (tipping bucket) }\end{array}$ & $\begin{array}{l}\text { 5-min interval } \\
\text { (tipping bucket) }\end{array}$ & $\begin{array}{l}\text { 1-min interval } \\
\text { (tipping bucket) }\end{array}$ \\
\hline
\end{tabular}

${ }^{\mathrm{a}}$ 1-h resolution before 1993. ${ }^{\mathrm{b}}$ 1-h resolution transport rate data have been validated. ${ }^{\mathrm{c}}$ Depositions are surveyed after periods with one to several high flow events. ${ }^{\mathrm{d}}$ Data with 1-h resolution used during gaps of 5-min resolution dataset.

Table 3. Description of events considered in this study.

\begin{tabular}{|c|c|c|c|}
\hline Catchment & Events defined for the study catchment & Corresponding rainfall parameters calculated $*$ & Period of occurrence \\
\hline Erlenbach (Alptal) & $\begin{array}{l}210 \text { large bedload events } \\
69 \text { small bedload events } \\
2538 \text { no-bedload events }\end{array}$ & $\begin{array}{l}P_{\mathrm{T}}, D_{\mathrm{T}}, I_{\mathrm{T}}, P_{\mathrm{BLS}}, D_{\mathrm{BLS}}, I_{\mathrm{BLS}} \\
P_{\mathrm{T}}, D_{\mathrm{T}}, I_{\mathrm{T}}, P_{\mathrm{BLS}}, D_{\mathrm{BLS}}, I_{\mathrm{BLS}} \\
P_{\mathrm{T}}, D_{\mathrm{T}}, I_{\mathrm{T}}\end{array}$ & $\begin{array}{l}1986-1999 / 2003-2009 \\
1986-1999 / 2003-2009 \\
1986-1999 / 2003-2009\end{array}$ \\
\hline Vogelbach (Alptal) & 26 bedload events & $P_{\mathrm{T}}, D_{\mathrm{T}}, I_{\mathrm{T}}, P_{\mathrm{BLS}}, D_{\mathrm{BLS}}, I_{\mathrm{BLS}}$ & $2003-2009$ \\
\hline Rio Cordon & $\begin{array}{l}16 \text { bedload events } \\
249 \text { no-bedload events }\end{array}$ & $\begin{array}{l}P_{\mathrm{T}}, D_{\mathrm{T}}, I_{\mathrm{T}}, P_{\mathrm{BLS}}, D_{\mathrm{BLS}}, I_{\mathrm{BLS}} \\
P_{\mathrm{T}}, D_{\mathrm{T}}, I_{\mathrm{T}}\end{array}$ & $\begin{array}{l}1986-2002 \\
2001-2002\end{array}$ \\
\hline Laval (Draix) & $\begin{array}{l}64 \text { bedload events } \\
490 \text { non-erosive events }\end{array}$ & $\begin{array}{l}P_{\mathrm{T}}, D_{\mathrm{T}}, I_{\mathrm{T}} \\
P_{\mathrm{T}}, D_{\mathrm{T}}, I_{\mathrm{T}}\end{array}$ & $\begin{array}{l}1985-2003 \\
1985-2003\end{array}$ \\
\hline Moulin (Draix) & $\begin{array}{l}54 \text { bedload events } \\
476 \text { non-erosive events }\end{array}$ & $\begin{array}{l}P_{\mathrm{T}}, D_{\mathrm{T}}, I_{\mathrm{T}} \\
P_{\mathrm{T}}, D_{\mathrm{T}}, I_{\mathrm{T}}\end{array}$ & $\begin{array}{l}1988-2003 \\
1988-2003\end{array}$ \\
\hline
\end{tabular}

${ }^{*} P_{\mathrm{T}}$ is the total accumulated event rainfall and $P_{\mathrm{BLS}}$ the accumulated rainfall until bedload transport start (mm); $D_{\mathrm{T}}$ is the overall rainfall duration and $D_{\mathrm{BLS}}$ the rainfall duration until bedload transport start $(\mathrm{h}) ; I_{\mathrm{T}}$ is the mean rainfall intensity for entire events and $I_{\mathrm{BLS}}$ the mean rainfall intensity until bedload transport start (mm $\mathrm{h}^{-1}$ ).

only considered bedload activity that took place from May through October when the contribution of snowmelt to stream discharge is negligible.

\subsubsection{Rainfall data}

Precipitation data for the Erlenbach and Vogelbach are acquired from automatic rain gauges (heated Lambrecht tipping bucket gauges) located within the two catchments at a temporal resolution of $10 \mathrm{~min}$ (Table 2) (Hegg et al., 2006). The rain gauges measure rainfall at a resolution of $0.1 \mathrm{~mm}$. The collected data are expected to be representative for the two catchments when concerning their moderate dimensions.

For precipitation causing bedload transport (large and small events), the rainfall amount was summarized both for the duration until the onset of transport as well as until the end of the rainfall. For the other precipitation events that did not trigger any bedload transport (no-bedload events), total rainfall amount and duration was registered. An antecedent 2-h timeframe with practically no rainfall was required for the definition of a distinct rainfall event. As an additional restriction to account for condensation due to fog or dew, the sum of recorded rainfall in the 2-h timeframe separating rainfall events has to be no more than $0.1 \mathrm{~mm}$. In other studies focusing on debris flows, longer intermediate periods with no appreciable rainfall of, for example, $6 \mathrm{~h}$ (Deganutti et al., 2000; McArdell and Badoux, 2007) or $12 \mathrm{~h}$ (Johnson and Sitar, 1990) were chosen. However, the fast hydrologic response of the small Erlenbach and Vogelbach catchments as well as the relatively wet atmospheric conditions that characterize the upper Alptal require the consideration of a shorter timeframe.

The different variables describing the investigated precipitation events are (cf. Table 3):

1. Total accumulated event rainfall $P_{\mathrm{T}}(\mathrm{mm})$

2. Rainfall duration (total event) $D_{\mathrm{T}}(\mathrm{h})$

3. Mean rainfall intensity for entire event $I_{\mathrm{T}}\left(\mathrm{mm} \mathrm{h}^{-1}\right)$ 
4. Accumulated rainfall until bedload transport start $P_{\mathrm{BLS}}$ $(\mathrm{mm})$

5. Rainfall duration until bedload transport start $D_{\mathrm{BLS}}$ (h)

6. Mean rainfall intensity until bedload transport start $I_{\mathrm{BLS}}$ $\left(\mathrm{mm} \mathrm{h}^{-1}\right)$.

\subsection{Rio Cordon catchment (Italy)}

\subsubsection{Experimental research site}

The Rio Cordon is a small headwater catchment in the Eastern Italian Alps (Dolomites), near the town of Selva di Cadore in the Veneto region (Fig. 1). With a catchment size of $5 \mathrm{~km}^{2}$, the Rio Cordon is considerably larger than the other catchments investigated in our study (Table 1). However, about $50 \%$ of the total sediment source area (mainly bare slopes, shallow landslides and minor debris-flow channels) is located upstream of a low-gradient belt where sediment deposition takes place, thus making sediment supply from the upper part of the basin of minor relevance (Lenzi et al., 2004; Mao et al., 2009). The basin is only slightly forested in its lowest part (7\% forest and $18 \%$ shrub cover), mainly due to its high elevation, and is dominantly covered by alpine grasslands $(61 \%)$, while $14 \%$ of the area is bare. Geologically, the Rio Cordon is chiefly characterized by dolomites, volcaniclastic conglomerates and tuff sandstones. Moreover, quaternary deposits are common in the basin. The main physiographic characteristics of the catchment are given in Table 1 . The Rio Cordon is characterized by a boulder-bed, step-pool and cascade morphology, and the mean channel slope is $13.6 \%$. For further information on the catchment, the reader is referred to the studies of Lenzi et al. (2004) and Mao et al. (2009, 2010).

\subsubsection{Sediment transport data}

Streamflow, suspended sediment and solid transport have been monitored at the Rio Cordon since 1986 (Lenzi et al., 1999, 2004). Downstream of an inlet channel, an inclined grid separates coarse bedload $(>20 \mathrm{~mm}$ ) from fine bedload and water. Coarse material is deposited in a storage area while water and fine sediment is diverted to a settling basin via an outlet channel. The volume of coarse bedload is measured at 5 -min intervals (1-h resolution before 1993) by 24 ultrasonic sensors fitted on a fixed frame over the storage area (Table 2). Finer bedload fractions $(<20 \mathrm{~mm})$ are quantified by loading cells that measure the pressure of the material deposited in a settling basin situated downstream of the outlet channel (e.g. Lenzi et al., 1999, 2004), but they are not considered in this study.

Overall, 24 bedload transport events were recorded from 1986 to 2006 (Lenzi et al., 2004; Mao et al., 2008). An intense flood occurred on 14 September 1994, featuring a peak water discharge of $10.4 \mathrm{~m}^{3} \mathrm{~s}^{-1}$ and a peak bedload transport rate of about $25 \mathrm{~kg} \mathrm{~s}^{-1} \mathrm{~m}^{-1}$. It represents a geomorphic threshold for the Rio Cordon basin, since it has altered the stream bed geometry (Lenzi, 2001) and the sediment-supply characteristics of the basin as a whole (Lenzi et al., 2004). In the present study, only flood events which transported bedload volumes higher than $1 \mathrm{~m}^{3}$ were considered. The selected 16 events are either flashy summer floods generated by convective rainfalls or longer events produced by autumn prolonged rainfalls. Peak flows and bedload volumes range from 1.5 to $10.4 \mathrm{~m}^{3} \mathrm{~s}^{-1}$ and 1.0 to $900 \mathrm{~m}^{3}$, respectively.

\subsubsection{Rainfall data}

In the Rio Cordon, precipitation data is acquired with $0.1 \mathrm{~mm}$ resolution from an automatic tipping bucket rain gauge located near the experimental station. A further rain gauge is located in the middle of the basin (Mondeval), but because of numerous missing data it was mainly used to check the precipitation measured at the closing section of the experimental basin.

Duration and accumulated and mean rainfall values before the beginning of bedload transport ( $P_{\mathrm{BLS}}, D_{\mathrm{BLS}}$ and $\left.I_{\mathrm{BLS}}\right)$ were determined similarly as for the Alptal catchments. 5min data was used where available and hourly data where 5 -min data was missing. Of the overall 16 triggering rainfall events considered, eight are described with 5-min data. Also, total rainfall amount $\left(P_{\mathrm{T}}\right)$ and duration $\left(D_{\mathrm{T}}\right)$ were registered and mean intensity $\left(I_{\mathrm{T}}\right)$ calculated for all the storms with bedload transport. No-bedload events, i.e. rainfall periods that did not cause enough discharge in the channel to generate bedload transport, were only calculated for selected years (cf. below; Table 3).

\subsection{Laval and Moulin catchments (Draix experimental site, France)}

\subsubsection{Experimental research site}

The experimental site of Draix, where hydrological and geomorphological research has been carried out for more than $25 \mathrm{yr}$, is located in the Southern French Alps near the town of Digne-les-Bains (Fig. 1). Measurement of rainfall, discharge and solid transport was started in 1983/1984 in five small catchments, four of which were continuously monitored, while no measurements were taken in the fifth catchment between 1993 and 2009 (Mathys et al., 2003, 2005). The catchments vary in size as well as in land cover. The Draix site is situated in the Black Marls Formation with easily erodible bedrock (Antoine et al., 1995). Under the influence of a severe climate that can be described as Mediterranean mountainous, featuring freezing in winter and heavy rainfall in summer and early autumn, a typical badland morphology has been formed. Catchments in the area are characterized by numerous gullies and rills and considerable bedload transport during floods, often in the form of hyperconcentrated flows. 
In the present study, we focus on the two neighbouring catchments Laval and Moulin (Table 1). The Laval $\left(0.86 \mathrm{~km}^{2}\right)$ is only sparsely vegetated and shows numerous sub-basins that drain into a main channel of approximately $1 \mathrm{~km}$ length (Mathys et al., 2003). The Moulin is a much smaller intermediate scale basin $\left(0.09 \mathrm{~km}^{2}\right)$ with a distinct channel network and a main stream of $300 \mathrm{~m}$ length (Mathys et al., 2005). In both catchments the hillslope gradients are markedly higher than the channel gradients.

\subsubsection{Sediment transport data}

At the outlet of both catchments, just upstream of the discharge gauging station, sediment traps are installed that retain coarse material and a small fraction of the finer sediments. Depositions are surveyed applying topographic methods after single flood events or periods with several high flows (Table 2). The minimum deposited sediment volume that can be detected is $5-10 \mathrm{~m}^{3}$ for the Laval and $1 \mathrm{~m}^{3}$ for the Moulin. For the Moulin sediment trap, some deposits under $1 \mathrm{~m}^{3}$ can be evaluated if the trap had been emptied before the flood.

In the present study we considered bedload events that occurred from April through October to exclude any influence by snowmelt. Moreover, we only took into account single events, i.e. trap deposits corresponding to a single flood and not several consecutive floods. This allows for a clear definition of the triggering rainfall. As for the Alptal catchments and the Rio Cordon, only flood events which transported bedload volumes above a threshold value of $1 \mathrm{~m}^{3}$ were considered here (which applied to all Laval events that met the above mentioned requirements and to $3 / 4$ of the events in the much smaller Moulin). Peak flows of the selected events range from less than 0.10 to $19.3 \mathrm{~m}^{3} \mathrm{~s}^{-1}$ for the Laval catchment and from less than 0.05 to $1.82 \mathrm{~m}^{3} \mathrm{~s}^{-1}$ for the Moulin catchment. The largest bedload volume (trap deposit) in our dataset amounts to $700 \mathrm{~m}^{3}$ in the Laval and to $57 \mathrm{~m}^{3}$ in the Moulin.

No-bedload events could not be determined in a comparable way to the Erlenbach and Rio Cordon. A class of events which we here call non-erosive was determined in a previous study (unpublished data, 2012). In a first step, erosive events leading to bedload movement (but not necessarily to bedload deposition in the sediment traps) were identified. In contrast, all other precipitation events leading to - generally small - floods without bedload movement were classified as non-erosive events (cf. below).

\subsubsection{Rainfall data}

The rainfall recorder in the lower part of the two neighbouring Moulin and Laval catchments measures precipitation that is considered to be representative for both catchments. The rain gauge is a tipping bucket device with a resolution of
$0.2 \mathrm{~mm}$. The data are registered with a one minute time step (Table 2).

\section{Rainfall thresholds for bedload transport initiation}

\subsection{Alptal catchments}

\subsubsection{Erlenbach}

The Erlenbach features the most extensive dataset of our study with a total of 279 considered sediment transport events that took place within a 21 -yr period (Table 3). 210 of these events led to considerable bedload transport, and the remaining 69 are considered small events. Due to its comprehensive and wide-spanning nature, we regard the Erlenbach database as our reference dataset throughout this paper.

In Fig. 2a, rainfall duration $D_{\mathrm{BLS}}$ is plotted against mean rainfall intensity $I_{\mathrm{BLS}}$ for rainfall events that lead to transport. In addition, rainfall events that did not trigger bedload transport - the so-called no-bedload events - are shown on the diagram. The large transport events with an estimated bedload volume of at least $1 \mathrm{~m}^{3}$ cover a relatively well defined area in Fig. 2a. The data points display a fairly small scatter in intensity for a given duration. However, the rainfall duration spans almost three orders of magnitude from $20 \mathrm{~min}$ to about $18 \mathrm{~h}$. On the contrary, no-bedload events span over a considerably larger range of both rainfall intensity and duration. The small bedload events cover an area similar to the large events but do not occur as a consequence of very intensive bursts of more than $20 \mathrm{~mm} \mathrm{~h}^{-1}$.

We defined by eye a lower envelope intensity-duration threshold line for the onset of sediment transport in the Erlenbach the way it has often been done in natural hazard research for mass movement activity (Guzzetti et al., 2008). Above this threshold line bedload transport may be expected to occur. The rather limited spread of rainfall intensities for a certain duration observed in the data of both large and small events facilitated the task.

The three precipitation events that led to considerable sediment transport and that are located below the intensityduration threshold line (Fig. 2a) were studied individually. The event that deviates the most from the threshold line was an evening thunderstorm that occurred in July 1995. The highly convective nature of the event with a variable rainfall pattern is confirmed by the fact that the rainfall peak was recorded after the onset of a steep rising limb of the hydrograph. Most probably the peak rainfall intensity bypassed the instruments and was not recorded. The two other events that plot below the rainfall intensity-duration line (Fig. 2a) both took place in late May (1987 and 1988). The former had a very low intensity $\left(I_{\mathrm{BLS}} \approx 4 \mathrm{~mm} \mathrm{~h}^{-1}\right.$ ) and was very probably influenced by additional runoff generated by snowmelt in the uppermost portion of the catchment, which is confirmed by a very low water temperature compared to normal values for 


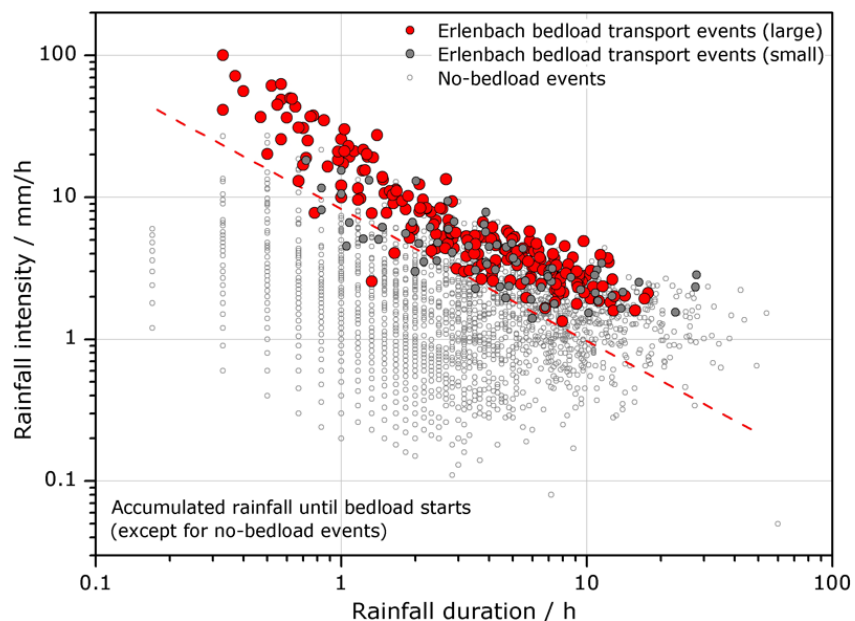

(a)

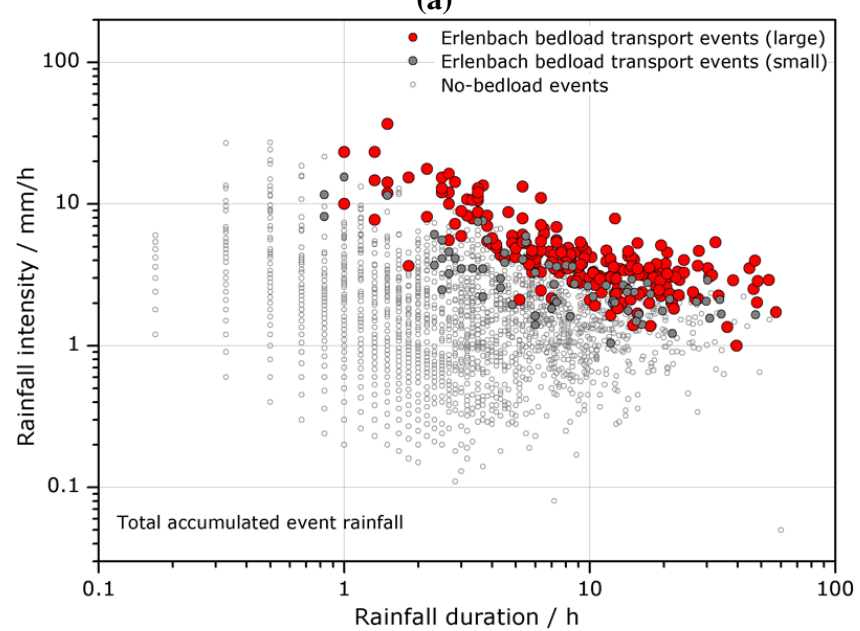

(b)

Fig. 2. (a) Intensity-duration relationship $I_{\mathrm{BLS}}-D_{\mathrm{BLS}}$ for rainfall (recorded until beginning of bedload) that triggered large (red dots) and small (grey dots) amounts of bedload transport in the Erlenbach catchment. The threshold line is manually fitted and applies to the large transport events; (b) Intensity-duration relationship $I_{\mathrm{T}^{-}}$ $D_{\mathrm{T}}$ for rainfall (recorded for the entire event) that triggered large and small amounts of bedload transport in the Erlenbach catchment. Grey circles in (a) and (b) indicate rainfall events that did not lead to bedload transport at all.

the season and by the discharge hydrograph. The second rainfall event $\left(I_{\mathrm{BLS}} \approx 8 \mathrm{~mm} \mathrm{~h}^{-1}\right)$ was short and convective, and also had a highly variable rainfall pattern which presumably led to an inaccurate (too low) measurement of the rainfall amount $P_{\mathrm{BLS}}$.

Each rainfall that generated both large and small amounts of bedload was also selected for Fig. 2b, where total rainfall duration for the entire event $D_{\mathrm{T}}$ is plotted against the corresponding mean rainfall intensity $I_{\mathrm{T}}$. Naturally, the rainfall events as displayed in Fig. $2 b$ become longer than in Fig. 2a in most of the cases. Also, the mean intensities $I_{\mathrm{T}}$ decrease on average in comparison to the $I_{\mathrm{BLS}}$ values in Fig. 2a. The threshold region is slightly better defined in Fig. 2a. The main reason for showing both approaches (cumulated rainfall until bedload transport starts and for the total events) is to verify comparability with results provided by other test sites. The exact moment of onset of transport is not known in all our catchments and thus the determination of $I_{\mathrm{BLS}}$ and $D_{\mathrm{BLS}}$ is not possible there (cf. Sects. 3.3, 3.4 and 4.1).

No rainfall event with a mean intensity $I_{\mathrm{BLS}}$ below 1.3 $1.6 \mathrm{~mm} \mathrm{~h}^{-1}$ has been observed to lead to sediment transport (Fig. 2a). Events that lasted longer than 8 hours once bedload transport started all show mean rainfall intensities of at least $1.6 \mathrm{~mm} \mathrm{~h}^{-1}$. Thus, the threshold line for long-lasting precipitation events is controlled by intensity only. This leads to the formation of a break-point in the rainfall intensity-duration data that cannot be described by a single line. This phenomenon is also discernible in the data of other catchments, as will be shown below. Very long-lasting rainfall events with low mean intensities (below 1.3-1.6 $\mathrm{mm} \mathrm{h}^{-1}$ ) cause (partly steady) discharges at the Erlenbach that are not able to initiate bedload transport, regardless of their duration. This might mark a difference to the triggering of slope failures that can eventually occur as a result of long-lasting rainfall, albeit at low intensities. However, Fig. 2a also shows that such rainfall events are not frequent in the Alptal, and only a few no-bedload events are observed with both $D_{\mathrm{BLS}}>10 \mathrm{~h}$ and $I_{\mathrm{BLS}}<1.6 \mathrm{~mm} \mathrm{~h}^{-1}$ conditions.

\subsubsection{Vogelbach}

In Fig. 3a and $b$, the 26 rainfall events that led to bedload transport in the nearby Vogelbach during the period from 2003 to 2009 are illustrated. The Vogelbach dataset is smaller than the Erlenbach set because geophone measurements started much later (Table 3). For the purpose of comparison, mean intensity and duration of the events associated with transport in the Erlenbach during the Vogelbach observation period are also plotted in the figures.

The data suggests that bedload transport is more frequent in the Erlenbach than in the Vogelbach, as more than twice as many transport events (57) were observed in the Erlenbach from 2003 to 2009. However, because the direct calibration of the geophone sensors is not possible at the Vogelbach and bedload volumes are thus estimated using external data, this statement has to be treated with caution. Regardless of their number, the rainfall events that lead to bedload transport in the Vogelbach exhibit very similar characteristics compared to the sediment producing events in the Erlenbach. The data of the two Alptal catchments show an analogue distribution of data points and approximately cover the same data range (Fig. 3a). The threshold line defined for the Vogelbach is similar to the one for the Erlenbach (based on all 210 large Erlenbach events, cf. Fig. 2a). For simplicity we will use the latter throughout the remainder of the article. When considering the total event rainfall (Fig. 3b), the distribution of the data points of the two catchments differs in the sense that 


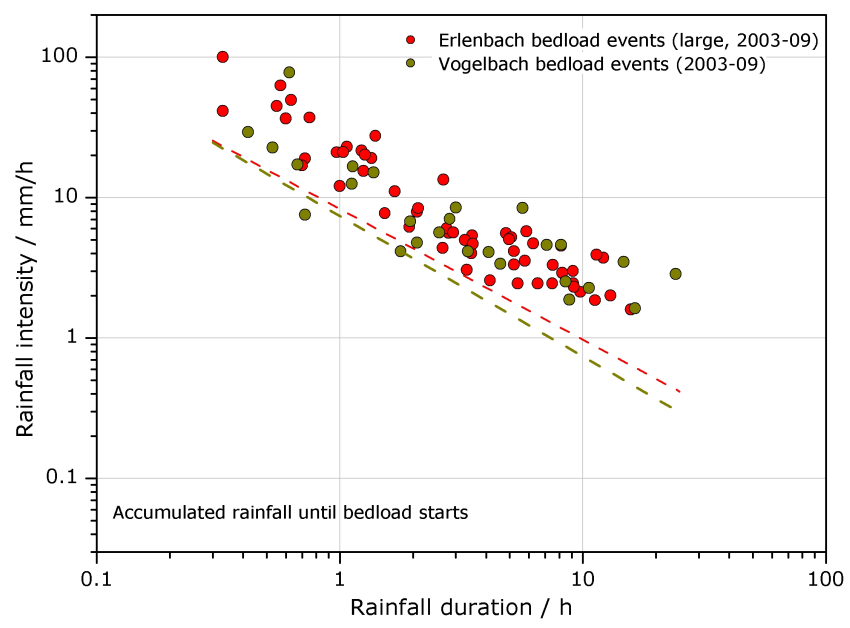

(a)

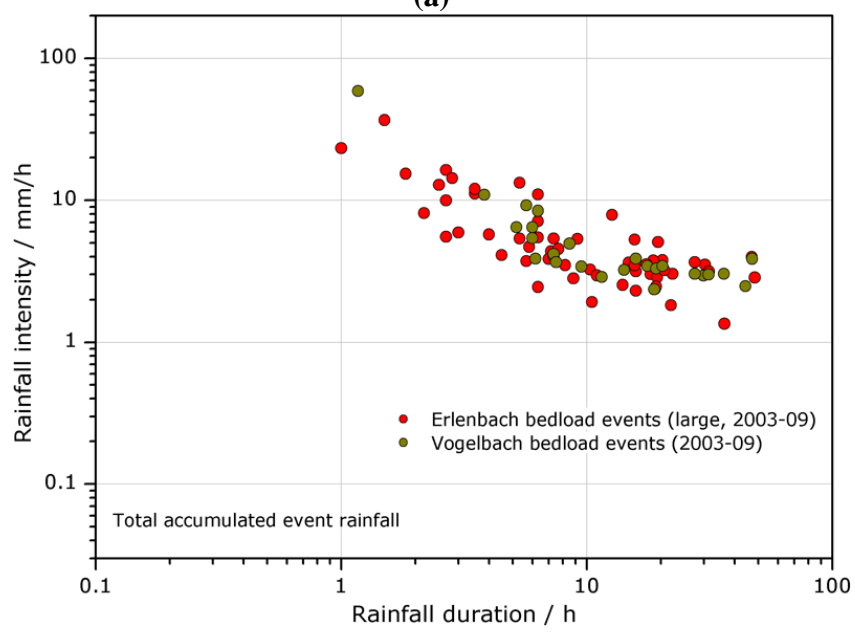

(b)

Fig. 3. (a) Intensity-duration relationship $I_{\mathrm{BLS}}-D_{\mathrm{BLS}}$ for rainfall (recorded until beginning of bedload) that triggered large amounts of bedload in the Vogelbach (green dots) and Erlenbach (red dots) catchments during the 2003-2009 period only (cf. Table 3). The red threshold line is identical with the line in Fig. 2a (Erlenbach) whereas the green threshold line is manually fitted for the Vogelbach data only; (b) Intensity-duration relationship $I_{\mathrm{T}}-D_{\mathrm{T}}$ for rainfall (recorded for the entire event) that triggered large amounts of bedload transport in the Erlenbach (red dots) and the Vogelbach (green dots) catchments during the 2003-2009 period.

short events - shorter than ca. $5 \mathrm{~h}$ - are underrepresented in the Vogelbach compared to the Erlenbach.

\subsection{Rio Cordon}

Regarding bedload transport, the Rio Cordon is considerably less active than the Alptal catchments. In the 17-yr observation period, only 16 transport events with bedload volumes larger than $1 \mathrm{~m}^{3}$ were recorded in the Dolomite catchment, corresponding to an average frequency of less than one event per year (in comparison to 10 events per year in the Erlenbach).

For the Rio Cordon, we applied the same diagram type as for the Alptal catchments, plotting rainfall duration against mean rainfall intensity (Fig. 4). The different colours used in the plots refer to the temporal resolution of the rainfall data (5-min and 1-h resolution depending on data availability). However, there does not seem to be any systematic difference in the properties of the two data types. Because of recurring data gaps in the rainfall dataset during early observation years, no-bedload events (rainfall events during which bedload transport was not detected) in the Rio Cordon were not computed for the entire study period. We determined nobedload events for the two years from 2001 to 2002 (Fig. 4a). Rainfall events that led to large amounts of sediment transport during the same period are highlighted by circles around the data points.

In the Rio Cordon, rainfall events leading to floods transporting considerable amounts of bedload are mostly of the long-duration type with typical durations of at least four to five hours and up to about forty hours. There is only one exception to this general pattern $\left(I_{\mathrm{BLS}}=19 \mathrm{~mm} \mathrm{~h}^{-1} ; D_{\mathrm{BLS}}=\right.$ $0.25 \mathrm{~h}$ ), which corresponds to a relatively small event in terms of total volume transported $\left(6.2 \mathrm{~m}^{3}\right)$ (Fig. 4a). Otherwise, high-intensity/thunderstorm-type precipitation has never led to important bedload transport during the observation period. The scatter of the intensity-duration data is thus rather small for rainfall events leading to bedload transport (when neglecting the one high-intensity event). Similarly to the Erlenbach data, however, both mean intensity and duration of the no-bedload events span over a larger range (Fig. 4a).

When plotting total rainfall duration for the entire event $D_{\mathrm{T}}$ against the corresponding mean rainfall intensity $I_{\mathrm{T}}$, instead of $I_{\mathrm{BLS}}$ and $D_{\mathrm{BLS}}$, the range of data appears more compacted and the data points lie within one order of magnitude, at least regarding intensities (Fig. 4b). The one single event described above remains isolated from the other data points, but differences both in duration and intensity with the other events are smaller.

Similarly to the Alptal data, we defined a threshold line for the onset of bedload transport (Fig. 4a) in the Rio Cordon. The characteristics of the threshold line are obviously strongly affected by the single, short-duration/high-intensity event in the upper-left corner of the plot. The break-point observed in the Erlenbach data is also discernible in the Rio Cordon data. Here, the two lowest mean rainfall intensities until the beginning of bedload transport $I_{\mathrm{BLS}}$ that were recorded amount to 1.2 and $1.4 \mathrm{~mm} \mathrm{~h}^{-1}$, and no data points are located in the immediate vicinity of the threshold line for durations longer than $8-10 \mathrm{~h}$. In agreement to the observations made in the Erlenbach, such very low-intensity rainfall events with $D_{\mathrm{BLS}}>10 \mathrm{~h}$ are generally infrequent, as indicated by the few no-bedload events in this range (Fig. 4a). 


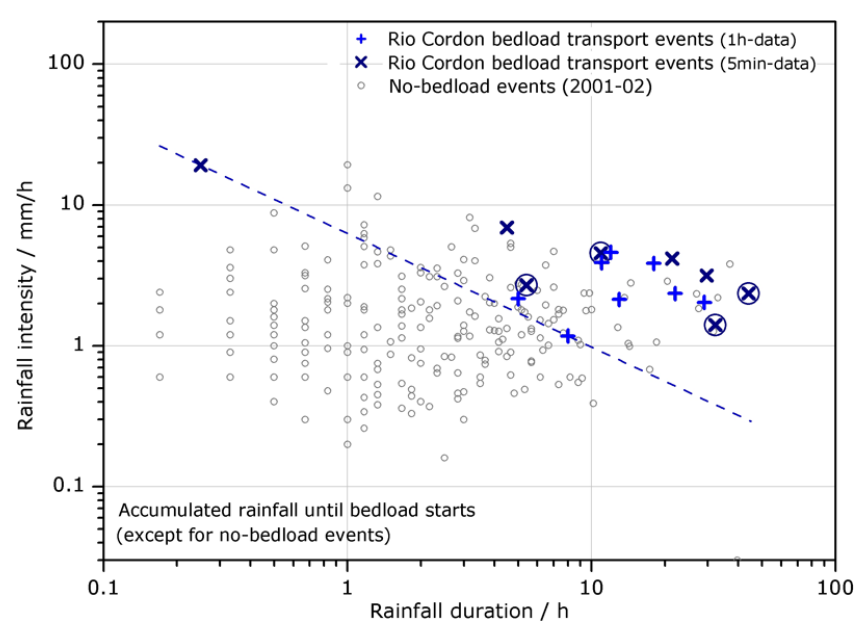

(a)

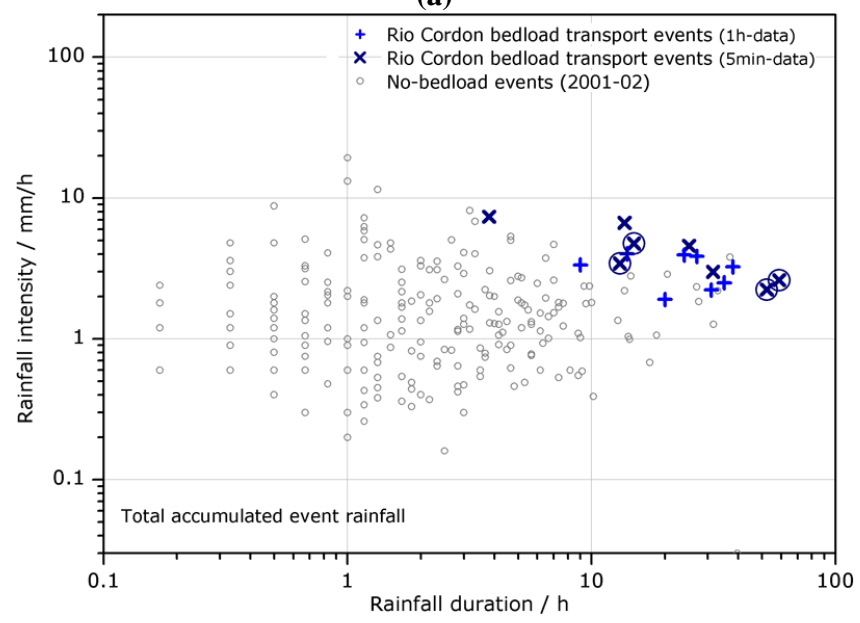

(b)

Fig. 4. (a) Intensity-duration relationship $I_{\mathrm{BLS}}-D_{\mathrm{BLS}}$ for rainfall (recorded until beginning of bedload) that triggered bedload transport in the Rio Cordon catchment for the entire study period (cf. Table 3). The threshold line is manually fitted; (b) Intensity-duration relationship $I_{\mathrm{T}}-D_{\mathrm{T}}$ for rainfall (recorded for the entire event) that triggered bedload transport in the Rio Cordon catchment. Rainfall events not leading to bedload transport (for the years 2001 to 2002 only) are marked by grey circles in (a) and (b). The four large blue circles indicate which rainfall events with bedload transport occurred during these two years.

\subsection{Draix catchments}

In the Draix catchments, instantaneous transport rates are not available and the exact time of bedload transport onset cannot be determined. Hence, $I_{\mathrm{BLS}}$ and $D_{\mathrm{BLS}}$ were not determined, and the intensity-duration relationship of rainfall events producing floods associated with bedload transport is presented for the entire length of events $\left(I_{\mathrm{T}}\right.$ and $D_{\mathrm{T}}$ in Fig. 5).

The characteristics of precipitation events in the Laval and Moulin catchments leading to bedload deposition in the downstream sediment traps are diverse and cover a wide range of intensity and duration (Fig. 5). Short total events

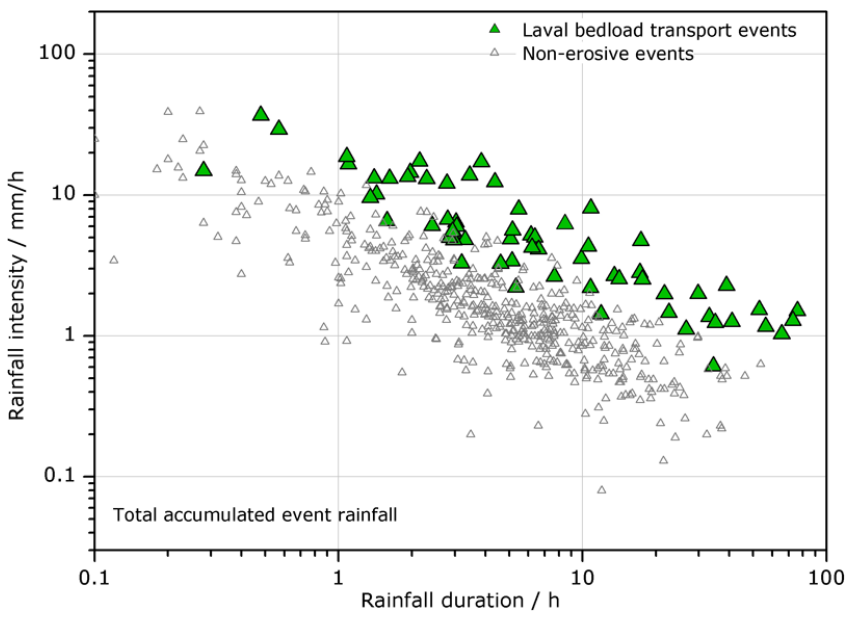

(a)

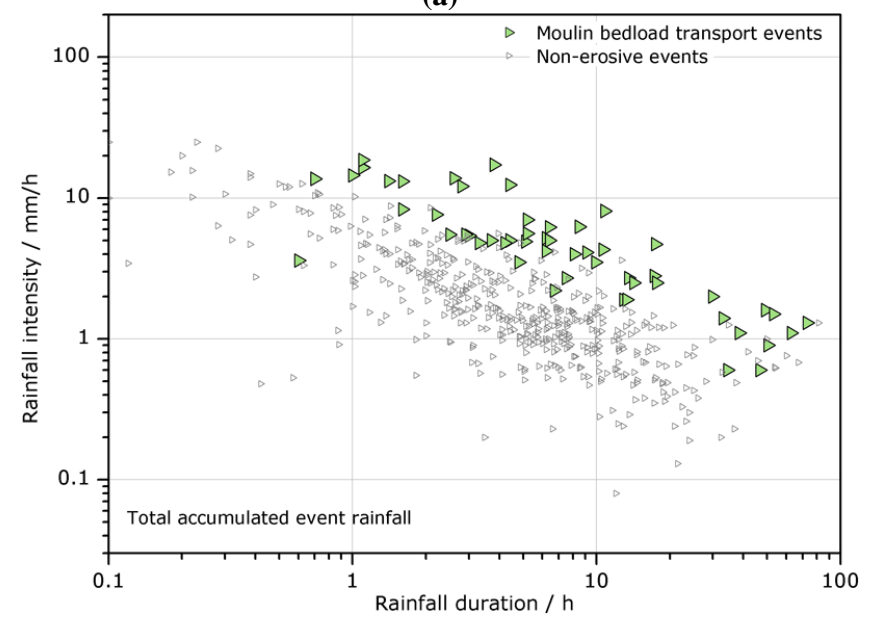

(b)

Fig. 5. (a) Intensity-duration relationship $I_{\mathrm{T}}-D_{\mathrm{T}}$ for rainfall (recorded for the entire event) that triggered bedload transport in the Laval catchment (Draix site). (b) Intensity-duration relationship $I_{\mathrm{T}}-D_{\mathrm{T}}$ for rainfall that triggered bedload transport in the Moulin catchment (Draix site). Non-erosive events are marked by small grey triangles in (a) and (b).

( $D_{\mathrm{T}}<$ approximately $3 \mathrm{~h}$ ) are well represented in the two Draix catchments, more than, for example, in the Alptal catchments. The same applies to very long events with low mean intensities $I_{\mathrm{T}}$, which are also well represented in the French study sites. A break-point in the intensity-duration data as observed for the other catchments is somewhat less pronounced for the data of the Laval and Moulin catchments (Fig. 5).

The Laval and Moulin catchments seem quite prone to bedload transport, as small precipitation events (in terms of total precipitation $P_{\mathrm{T}}$ ) tend to cause sediment motion in these two streams. This may be due to the fine sediments in the French catchments (Table 1). The material deposited in the channels or transported from the slopes is mainly constituted of plates of marls which are easily transported, even by 


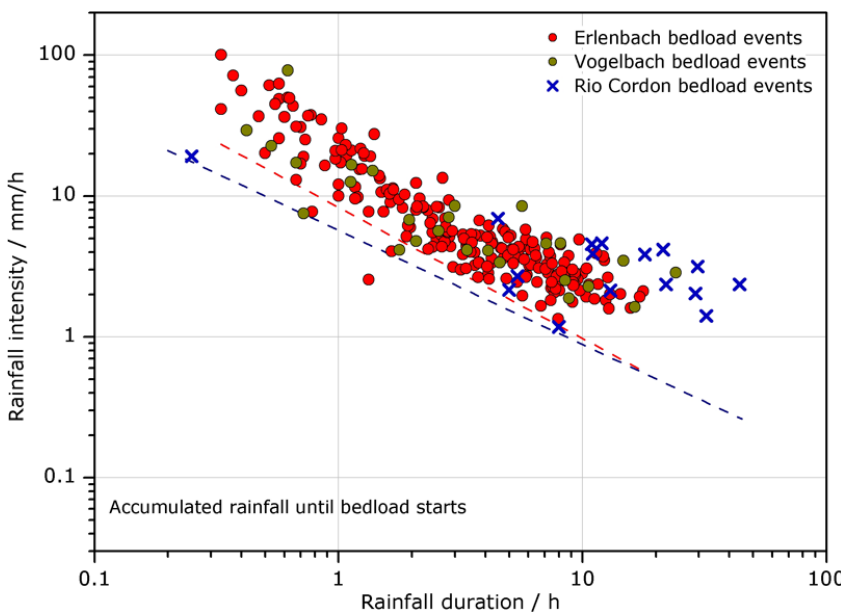

(a)

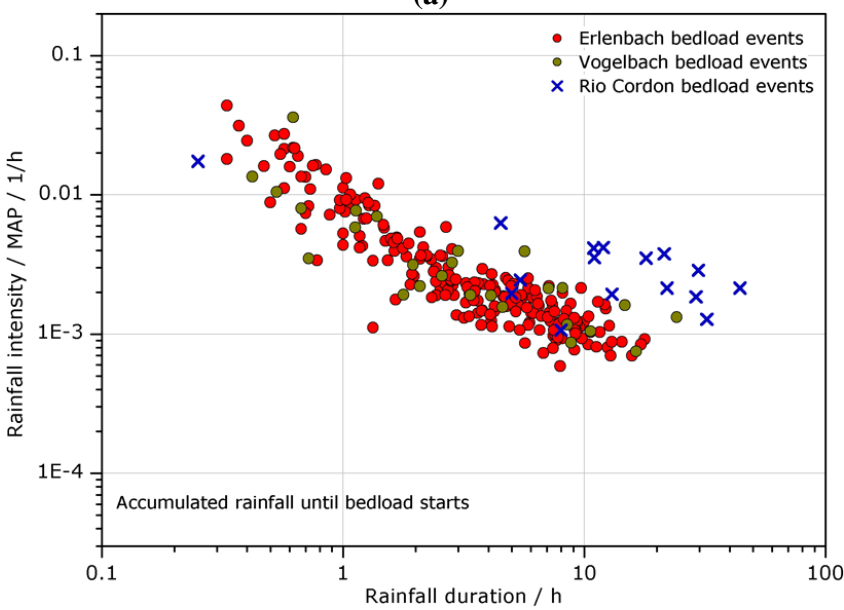

(c)

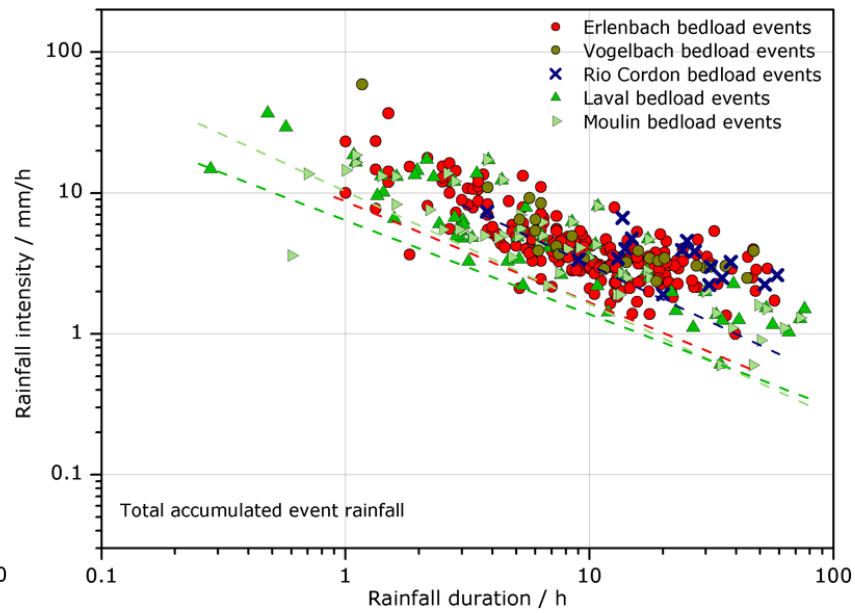

(b)

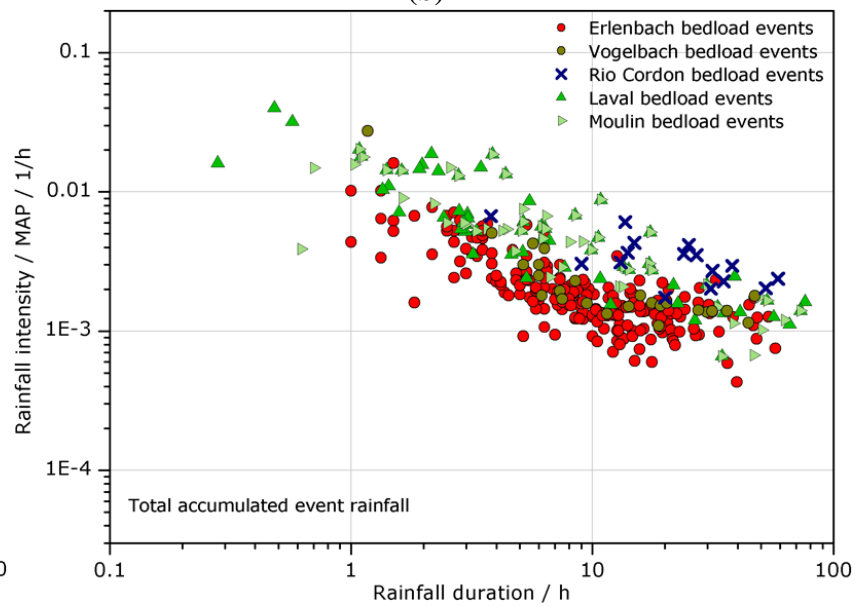

(d)

Fig. 6. Comparison of rainfall intensity-duration relationships in our study sites: (a) $I_{\mathrm{BLS}}-D_{\mathrm{BLS}}$ relationships for rainfall (recorded until beginning of bedload transport) in the Erlenbach, Vogelbach and Rio Cordon catchments; (b) $I_{\mathrm{T}}-D_{\mathrm{T}}$ relationships for total rainfall events associated with bedload transport in the Erlenbach, Vogelbach, Rio Cordon, Laval and Moulin catchments (the threshold lines are manually fitted); (c) and (d) show intensity data normalized by the mean annual precipitation MAP for rainfall until beginning of bedload transport and for total event rainfall related to bedload transport, respectively.

low flows. For the Moulin, the median grain size $d_{50}$ of the channel deposits ranges between 1.5 and $5 \mathrm{~mm}$, while $d_{90}$ (the size which is larger than $90 \%$ of the sediment) ranges between 5 and $33 \mathrm{~mm}$. For the Laval, $d_{50}$ ranges between 2 and $8 \mathrm{~mm}$, and $d_{90}$ between 8 and $37 \mathrm{~mm}$. On the other hand, sediment availability seems to play an important role in the Laval and Moulin catchments. The first spring storms of moderate intensity move material accumulated during the winter. With sufficient runoff in the channel network, the material is transported to the outlet and deposited in the traps. If runoff is too small, large amounts of sediments remain within the channels. High-intensity summer storms are able to move considerable amounts of sediment both in rills and the inter-rills and, as a consequence, to cause heavily loaded floods. Summer high flows are generally too short to move all the sediment and the amount of material in the channel net- work increases even though deposits at the outlet are large. Low-intensity storms in autumn produce less erosion on the slopes and lead to clearer flows that are able to mobilise sediment stocks and scour deposits notwithstanding their moderate size (Mathys et al., 2007). As a matter of fact, the critical discharge $Q_{\mathrm{c}}$ required to initiate the movement of the fine sediment in the Draix catchments is considerably lower than for the other study catchments (Table 1).

\subsection{Comparison of threshold rainfall conditions for different sites}

Rainfall intensity-duration threshold lines for the point in time of sediment transport onset were defined for two of the studied sites: the Alptal catchments (Erlenbach and Vogelbach) and the Rio Cordon in the Italian Dolomites (Table 3 and Fig. 6a). Even though the data point distributions of the 
Table 4. Defined intensity-duration threshold lines: values for the prefactor $K$ and exponent $\alpha$ in the equation $\left(I_{\mathrm{BLS}}=K D_{\mathrm{BLS}}^{-\alpha}\right)$.

\begin{tabular}{lrrrrr}
\hline \multirow{2}{*}{ Catchment } & \multicolumn{2}{c}{$\begin{array}{c}I_{\mathrm{BLS}}-D_{\mathrm{BLS}} \text { threshold line } \\
\text { (until start of bedload transport) }\end{array}$} & & \multicolumn{2}{c}{$\begin{array}{c}I_{\mathrm{T}}-D_{\mathrm{T}} \text { threshold line } \\
\text { (total rainfall) }\end{array}$} \\
\cline { 2 - 3 } \cline { 6 - 6 } \cline { 5 - 6 } & $K$ & $\alpha$ & & $K$ & $\alpha$ \\
\hline Erlenbach (Alptal) & 8.3 & 0.93 & & 8.7 & 0.72 \\
Vogelbach (Alptal) & 7.4 & 1.00 & & - & - \\
Rio Cordon & 6.3 & 0.81 & & 20.0 & 0.81 \\
Laval (Draix) & - & - & 6.4 & 0.66 \\
Moulin (Draix) & - & - & 10.3 & 0.80 \\
\hline
\end{tabular}

two experimental sites show important differences, the respective manually fitted threshold lines resemble each other quite closely. They are described by the following equation:

$$
I_{\mathrm{BLS}}=K \quad D_{\mathrm{BLS}}^{-\alpha}
$$

where $K$ is a constant and $\alpha$ an exponent empirically describing the catchment characteristics (e.g. for the Erlenbach $K=8.3$ and $\alpha=0.93$ ). Values of $K$ and $\alpha$ for all the threshold lines are listed in Table 4.

The Alptal threshold lines have a slightly higher negative slope and higher constant $K$ than the Rio Cordon line. This results in higher critical rainfall intensity values for events which quickly lead to bedload activity (shorter $D_{\mathrm{BLS}}$ ). Considering the differences in geology, climate, geomorphology, and catchment size of the Alptal streams and the Rio Cordon (Table 1), the threshold lines are surprisingly similar. Medium length durations of 3 to $10 \mathrm{~h}$ show very similar critical intensities.

Figure $6 \mathrm{~b}$ shows the precipitation data $\left(I_{\mathrm{T}}\right.$ and $D_{\mathrm{T}}$ recorded during entire events) associated with large bedload events of all the investigated Alpine catchments. Rainfall events in the Southern French Alps during which transport was recorded cover a wider rainfall duration range than events in the Swiss Prealps and a much wider range than events in the Dolomites. Nevertheless, the data clusters of the different catchments overlap with each other and no study site shows a data range that is isolated from the rest of the data. However, rainfall events associated with bedload transport in the Rio Cordon seem to have a fairly long duration in comparison to the data of the other catchments. With one exception they all last at least nine hours and result in high total event precipitation $P_{\mathrm{T}}$.

For the purpose of comparison, intensity-duration $\left(I_{\mathrm{T}}-\right.$ $D_{\mathrm{T}}$ ) threshold lines based on data for the entire duration of the rainfall events have been defined (Fig. 6b, Table 4). Such $I_{\mathrm{T}}-D_{\mathrm{T}}$ thresholds are obviously less suited for warning purposes, as they are related to the point in time when rainfall events stop and bedload transport has generally been under way for some time in a stream. Of course, this objection applies more to long-duration type events than to short and intensive thunderstorms, where it can happen that precipitation stops before the transport process begins.
Hence, a confrontation of precipitation data points referring to entire events and no-bedload events is not fully appropriate. Nevertheless, no-bedload/non-erosive events were added in Figs. 2b, 4b, 5a and 5b for the sake of completeness. Remember that in the Draix catchments (Fig. $5 \mathrm{a}$ and b) $I_{\mathrm{BLS}}$ and $D_{\mathrm{BLS}}$ cannot be determined. For the Erlenbach and Rio Cordon catchments, the separation of the no-bedload events from the precipitation events with bedload activity is more explicit when displaying $I_{\mathrm{T}}-D_{\mathrm{T}}$ data than when displaying $I_{\mathrm{BLS}}-D_{\mathrm{BLS}}$ data. This is not surprising, however, as duration increases faster than intensity decreases when moving from $I_{\mathrm{BLS}}-D_{\mathrm{BLS}}$ data to total data.

The small differences in data range between the Draix and Alptal sites are reflected in quite similar threshold lines with negative slopes (exponents) varying between 0.66 and 0.80 and constants varying between 6.4 and 10.3 (Table 4). With the lowest intercept and the highest exponent, the Laval site has the lowest critical rainfall for durations shorter than $30 \mathrm{~h}$. In contrast, the threshold line for the Rio Cordon differs from the other lines in the sense that it displays a much higher constant $K$, while its negative slope is comparable to the values of the other threshold lines (Table 4). This results in a much higher critical rainfall that is required to produce bedload transport in the Dolomite catchment. This could possibly be ascribed to the relatively stable morphology of the Rio Cordon channel bed (boulder-bed, step-pool and cascade) and the large observed characteristic grain sizes (Mao et al., 2009); this is especially true in comparison to the two Draix catchments with their markedly fine sediments.

The Alptal catchments have a mean annual precipitation (MAP) that is more than twice as large as the MAP in the Rio Cordon (Table 1). To account for this difference in climatic conditions, we normalized the rainfall intensity by MAP and plotted it against rainfall duration (Fig. 6c and d) as suggested by Guzzetti et al. (2008). Compared to the representation in ID space (Fig. 6a and b), the normalized data points scatter more along the $y$-axis. The normalized critical rainfall intensity values for bedload events in the Rio Cordon are much higher than in the Alptal catchments, underlining the fact that proportionally to the MAP, considerably more rainfall is needed in the Dolomite catchment to move bedload in the stream (Fig. 6c). This also applies when normalized $I_{\mathrm{T}}$ 
data is considered for all five catchments (Fig. 6d). The humid climate of the Alptal valley supplies the wet clay soils associated with the flysch geology with enough moisture. Fast runoff generation processes provide the channel with abundant discharge and, eventually, bedload transport, even during moderate precipitation events. In general, the threshold rainfall conditions for the onset of bedload transport are influenced both by the hydrologic response of a catchment and by its geomorphological characteristics. It is thus difficult to assess to what extent the inclusion of MAP in the ID analysis helps to improve the interpretation of threshold conditions between different catchments. We see some perspective to better explore the role of the hydrological response in our study sites by applying a rainfall-runoff model (cf. Sect. 4.1).

\section{Discussion}

\subsection{Threshold rainfall conditions and characteristics of sediment transporting floods}

Rainfall intensity-duration threshold lines for the different catchments or catchment groups in three different Alpine environments have been defined. Even though the presented database seems to be too scarce to make generally acceptable statements on typical rainfall characteristics for the triggering of bedload transport in mountain streams, the approach yields interesting results.

The comparison of the Erlenbach and Vogelbach rainfall datasets suggests a good transferability of the threshold line between streams located quite close to one another and therefore showing a similar climate, geology and soil characteristics. Furthermore, the comparison of the results from the Alptal and the Rio Cordon in the Dolomites (different climate and lithology) reveals a surprisingly similar threshold line for the critical rainfall at the time of transport onset. The similarity in threshold lines occurs even though a different data distribution can be observed in ID space (Fig. 6a). Because short events (shorter than $5 \mathrm{~h}$ ) are rare in the Rio Cordon dataset, the average and median duration of rainfall events causing bedload transport are considerably longer than in the Alptal. The mean accumulated rainfall until the start of bedload transport is more than twice as high in the Rio Cordon. Six of the 16 Rio Cordon rainfall events last for more than $20 \mathrm{~h}$ before sediment transport is detected. In contrast, the maximum values for $D_{\mathrm{BLS}}$ in the Erlenbach and Vogelbach amount to 17.8 and $24.1 \mathrm{~h}$ (only event $>20 \mathrm{~h}$ ), respectively (Fig. 6a). This difference can be certainly ascribed to the fact that the Rio Cordon has the larger basin area $\left(5 \mathrm{~km}^{2}\right.$, Table 1). Also, a topographical-geological threshold located in the middle of the basin (Mao et al., 2009) causes the headwater portion of the basin to provide only a minor contribution to the sediment yield of the lower part of the basin, where the measuring station is located. Thus, as in the case of glacially dominated basins (Brardinoni and Hassan, 2007), the drainage area be- comes an unreliable proxy for sediment supply, and a direct comparison between Alptal and Rio Cordon basins could be partially biased by the fact that in the Rio Cordon the upper part of the basin contributes directly to bedload generation only during major events. At last, it should be mentioned that very intense, convective rainfall events can be common in summertime in the Rio Cordon basin, and that because of its relatively large basin area, rainfall measured at the outlet station can not perfectly represent the average rainfall at the entire basin scale. Even though rainfall measured at the outlet station and at the Mondeval site in the middle of the catchment are generally in agreement, uneven rainfall distribution in the Rio Cordon could partially bias the comparison with the other Alpine basins.

To compare results from the Draix catchments with the other study sites, rainfall data for entire precipitation events was applied (Fig. 6b). Data from the Moulin and Laval are mainly characterized by a wide range in the intensityduration diagram and the presence of long-duration rainfall events with (very) low intensities. Differences in the results of the two experimental sites Draix and Alptal are definitely less noticeable than one could expect on grounds of different catchment characteristics (Table 1). In general, the Draix catchments seem to be slightly more prone to bedload transport than the other catchments. The shortduration/high-intensity bedload events in Laval and Moulin occur in summer. Even if the duration of the storm is short, the sediments stocks in the reaches close to the outlet can be moved quickly downstream to the sediment trap. Longduration/low-intensity events occur in April or October till November. Large amounts of sediment transported from the steep gully network during the summer are still available in the channels in autumn, and their moderate grain size allows transport by moderate discharges.

Our observations indicate that the threshold is not appropriately defined by a single power law function over the whole range of rainfall durations. Instead, the range of rainfall events leading to sediment transport within an intensityduration diagram can be delimited more accurately when applying three lines (Fig. 7). This applies particularly to the approach in which precipitation characteristics are described at the point in time when bedload motion begins in a stream.

In addition to the power law threshold line described by Eq. (1), the following two lines come into play (Fig. 7). (a) A line of constant (minimum) duration starting at a certain mean intensity $I_{\mathrm{BLS}}$ required to generate enough discharge for bedload transport. At the Alptal and Rio Cordon, the minimum duration amounts to 20 and $15 \mathrm{~min}$, respectively. For small catchments, it is expected that this value corresponds to the temporal resolution of the precipitation data in case of an extraordinarily intensive burst. In general, it depends on the hydrological characteristics of the catchment (mainly the reaction time). (b) A line of constant mean intensity for very long-duration rainfall events, which in the case of the Erlenbach and Rio Cordon corresponds to the above mentioned 


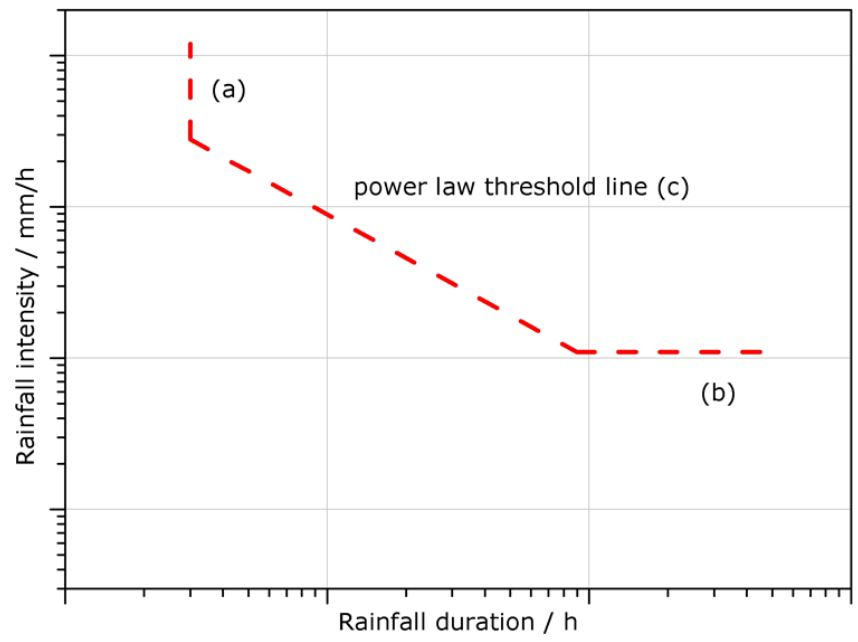

Fig. 7. Schematic illustration of the power law threshold line (c) (Eq. 1) and the intensity-dominated and duration-dominated domains delimited by the line of constant duration (a) and the line of constant mean intensity (b), respectively.

break-point (Sect. 3.1; see also Fig. 7). For the Alptal data, this intensity is at approximately $1.3 \mathrm{~mm} \mathrm{~h}^{-1}$, whereas for the Rio Cordon, it is at about $1.2 \mathrm{~mm} \mathrm{~h}^{-1}$. For both catchments the line of constant intensity starts after an event duration of around eight hours. The discharge resulting from smaller rainfall intensities is not able to mobilize any bedload. In contrast, streamflow generated at rainfall intensities just above the line of constant mean intensity (b in Fig. 7) should then correspond to the critical or threshold discharge at the start of bedload motion.

In the Erlenbach, when calculating the average of the intensities of precipitation events leading to bedload transport and lasting longer than eight hours, we obtain a value of $2.7 \mathrm{~mm} \mathrm{~h}^{-1}$, with single values ranging from 1.6 to $4.9 \mathrm{~mm} \mathrm{~h}^{-1}$. Combining these values with an estimated (direct) runoff coefficient of 0.4 , typical for long-duration precipitation of moderate total volume (Burch et al., 1996), we determine direct runoff values varying between 0.12 and $0.38 \mathrm{~m}^{3} \mathrm{~s}^{-1}$. Considering a characteristic baseflow of $0.035 \mathrm{~m}^{3} \mathrm{~s}^{-1}$, the resulting critical discharges vary between approximately 0.16 to $0.42 \mathrm{~m}^{3} \mathrm{~s}^{-1}$. However, note that discharge before the beginning of a rainfall event is highly variable depending on the antecedent rainfall. This range is slightly lower than the mean critical discharge for beginning of bedload transport $Q_{\mathrm{c}}$ observed at the Erlenbach $\left(0.49 \mathrm{~m}^{3} \mathrm{~s}^{-1}\right.$; see Table 1) but lies within the range of measured values (Turowski et al., 2011). In the Rio Cordon, precipitation events leading to sediment transport with a duration of more than eight hours show intensities of 1.4 to $4.6 \mathrm{~mm} \mathrm{~h}^{-1}$. Using characteristic values for a runoff coefficient $(0.33)$ and baseflow $\left(0.15 \mathrm{~m}^{3} \mathrm{~s}^{-1}\right)$ (unpublished data, 2012), we obtain resulting critical discharges that vary between 0.80 and $2.27 \mathrm{~m}^{3} \mathrm{~s}^{-1}$. The critical discharge at the be- ginning of bedload transport (for the median particle size) provided in Table $1\left(1.8 \mathrm{~m}^{3} \mathrm{~s}^{-1}\right)$ falls well within the determined range. Considering similar rainfall and runoff conditions in the two catchments, the somewhat larger observed

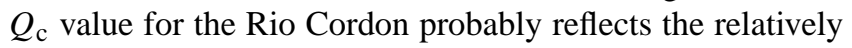
stable channel bed morphology and the larger catchment area as compared to the Erlenbach. These rough calculations suggest that it might be interesting to apply a rainfall-runoff model to calculate the critical discharge $Q_{\mathrm{c}}$ for given sets of precipitation intensity and duration values and to map the results in ID space. With this procedure the threshold lines for the onset of sediment transport defined here could be verified. However, this goes beyond the scope of the present investigation.

The intensity-duration exponents $\alpha$ in the intermediate domain for the Erlenbach (0.93) and the Rio Cordon (0.81) lie quite close to the value of 1.0. An exponent of 1.0 represents conditions where all precipitation events located on the threshold line have the same accumulated rainfall $P_{\mathrm{BLS}}$. This means that the onset of bedload motion in this domain is approximately independent of both intensity and duration, and instead only depends on the total volume of water delivered to the catchment. Thus, the relevant number of parameters can be reduced from two to one, which may be advantageous in some applications. On the other hand, the observed values of $\alpha<1$ imply that rainfall intensity is dominant over duration. That is, the same volume of water delivered over a long time period may not trigger an event, while it may trigger one when delivered over a short period. A value of $\alpha<1$ is commonly reported for threshold lines in the literature (e.g. Guzzetti et al., 2008) for shallow landslides and debris flows.

\subsection{Applicability for early warning purposes}

ID data from the streams show a relatively distinct boundary for the occurrence of bedload transport, and we were able to define threshold lines for critical rainfall characteristics that approximately delimit the lower envelope of bedload transport producing precipitation events. In the following analysis pertaining to early warning purposes, for reasons of practicability, we concentrate on the power law threshold curve and ignore the intensity- and duration-dominated domains as identified above ( $a$ and $b$ in Fig. 7; Sect. 4.1). In addition, clearly many of the bedload transport events plotted above the threshold lines defined in this contribution are not hazardous (e.g large floods with comparably small bedload volumes); however, in our data there is no systematic distribution of events in ID space according to the bedload volumes they transport. Thus, because no supplementary information for the determination of threshold lines arises from event size, we decided to take into consideration all available data points. The inclusion of non-hazardous floods probably gives a better definition of the thresholds. The threshold lines for the different small mountain streams have a similar appearance and thus a generalization seems practicable 
to a certain extent. A generalized line could be applied for particularly active torrents or mountain streams needing an early warning system but lacking discharge and direct bedload measurements.

However, our datasets indicate that it is not possible to distinguish straightforwardly between rainfall events that do or do not generate sediment transport. As shown in Fig. 2a for the Erlenbach, no-bedload events above the threshold line represent an obvious difficulty for warning purposes in potentially dangerous catchments.

We evaluated the Erlenbach data under this perspective and calculated hits, misses and false alarms as follows: (1) a hit represents a precipitation event that leads to bedload transport and is located above the determined threshold line; (2) if, instead, such a data point lies below the threshold line, a miss is counted; (3) a precipitation event not associated with bedload transport that is located above the threshold line represents a false alarm. By dividing the number of misses by the total number of events with bedload, the fraction of misses is obtained; by dividing the number of false alarms by the number of all the precipitation events above the threshold (i.e. the sum of hits and false alarms), the false alarm rate is obtained. To determine hits and misses, the $I_{\mathrm{BLS}}-D_{\mathrm{BLS}}$ data points and threshold line were used. We compared the precipitation characteristics of no-bedload events with the precipitation characteristics of events recorded until bedload transport starts, because any rainfall falling after this point in time will not have an effect on whether transport occurs at all. In addition, the use of a threshold line defined upon total accumulated event rainfall has to be avoided for warning purposes, because by the time the precipitation ends the majority of transported bedload can very well have reached the area at risk.

If the prefactor $K$ in Eq. (1) is varied, keeping the exponent $\alpha$ constant, the fraction of misses and the false alarm rate change considerably (Fig. 8). When considering the precipitation events that lead to bedload transport (both large and small magnitude transport), the fraction of misses remains below 0.01 with $K$ values of 5.7 or smaller. Beyond that value, the fraction of misses increases strongly with increasing $K$ to finally reach 0.99 at $K=37.7$. The false alarm rate decreases distinctively with increasing $K$ values, and reaches a low level of 0.50 to 0.56 for $13.6 \leq K \leq 28.8$. Note that the initial rise of the percentage of misses is much steeper than the initial drop of the false alarm rate (when comparing absolute values). At $K>30$ the false alarm rate considerably increases and reaches its maximum at 0.87 for $K=40.6$ (Fig. 8).

There is a general need to provide early warning with a high reliability (i.e. a minimum of false alarms) to prevent the desensitizing of the concerned public authorities and population to the problem. However, at the same time the prediction of all potentially hazardous bedload transport events in an active catchment (i.e. the avoidance of misses) is an even more important requirement when pursuing acceptance of an early

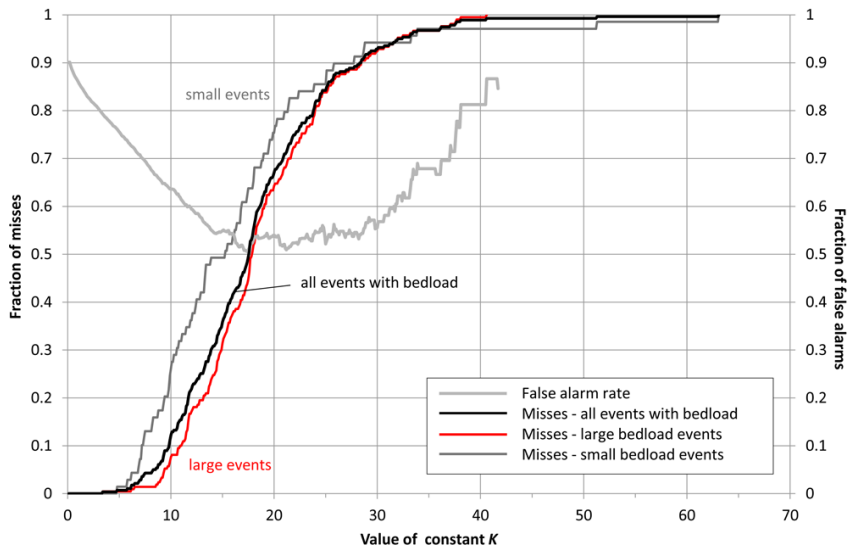

Fig. 8. Fraction of misses (rainfall events leading to bedload transport that lie below the threshold line divided by the total number of events with bedload) and fraction of false alarms for the Erlenbach stream as a function of the prefactor $K$ of the rainfall intensityduration threshold line (Eq. 1). Note that the false alarm rate is discontinued for values of $K>42$ because there are practically no more rainfall events with bedload transport above the threshold curve.

warning system by the general public. This is why we determined a relatively low constant $K$ of 8.3 in the rainfall intensity-duration threshold line for the Erlenbach stream associated with a very low fraction of misses $(0.01$ for the events with large bedload transport) but a considerably high false alarm rate of 0.67 .

Comparable values are reported in studies investigating the initiation of debris flows (cf. Sect. 4.3). In the Alpine Illgraben catchment located in the canton of Valais, Switzerland, about $50 \%$ of the rainfall events exceeding the empirical intensity-duration threshold cause debris flows that reach the populated areas (McArdell and Badoux, 2007). In the Moscardo catchment located in the Italian Alps the same value amounts to $35 \%$ for debris flows that reached the basin outlet (Deganutti et al., 2000), corresponding roughly to the false alarm rate established for the Erlenbach.

The rate of false alarms, though, is not the same for all types of precipitation events that occur in the Alptal. An analysis of the dataset indicates that for a rainfall duration of two hours or less, one third of all the data points that lie above the defined threshold line are no-bedload events eventually not producing bedload, and two thirds are bedload events (mostly large ones). For rainfall durations between two and ten hours, it is the other way around, with two thirds of all the events located above the threshold line being no-bedload events. Finally, for rainfall that lasts longer than ten hours, almost $90 \%$ of the data points above the threshold line are no-bedload events, and only in $10 \%$ of the cases bedload is ultimately activated. Similar considerations cannot be made for the Rio Cordon because of the small number of observations. During the 2001-2002 period for which no-bedload event data are available, a total of four transport events were 


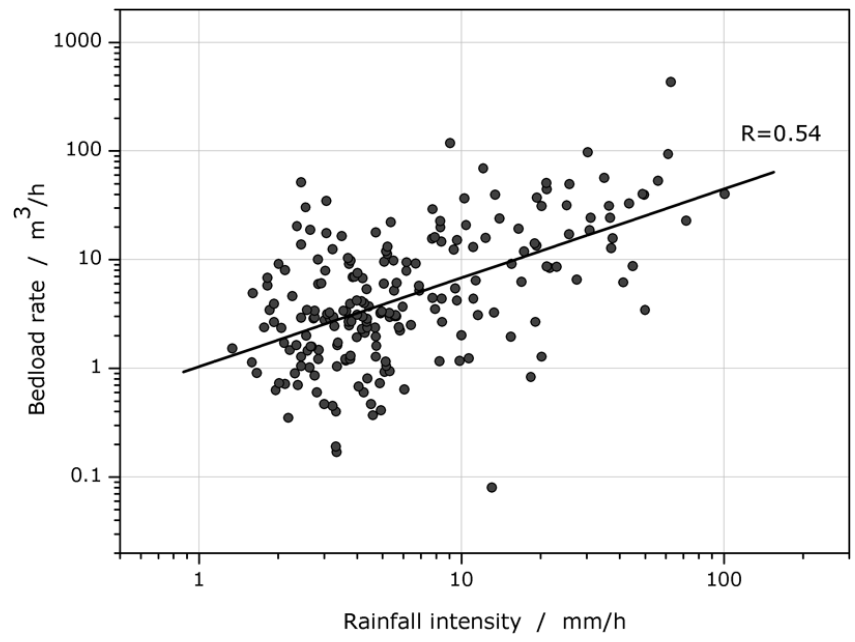

Fig. 9. Bedload rate plotted against mean rainfall intensity for all large bedload events recorded in the Erlenbach catchment (cf. Fig. 2a).

recorded. Three of them were triggered by storms with rainfall durations longer than ten hours, resulting in a false alarm rate of slightly more than $80 \%$; a value comparable to the one of the Erlenbach for the same type of long-duration precipitation events. For the Draix catchments the exact time of bedload transport onset cannot be determined. An in-depth analysis is thus not possible as $I_{\mathrm{T}}-D_{\mathrm{T}}$ thresholds are not well suited for warning purposes.

Overall, a considerable false alarm rate was detected mainly for long-duration, low-intensity rainfall in the Erlenbach. This implies a poor practicability of the rainfall intensity-duration curve approach for early warning purposes in such advective meteorological situations. On the contrary, a generalized threshold defining critical conditions for bedload transport initiation could represent a suitable basis for the prediction of dangerous situations in case of lowduration, high-intensity (convective) precipitation events. It can also be argued that such intensive events with a comparably smaller false alarm rate tend to be more dangerous in terms of total sediment volume transported. In the Erlenbach, average bedload rate during sediment transport events increases with increasing rainfall intensity (Fig. 9). Even though the scatter in the data is considerable, this probably reflects the fact that event bedload volumes in the Erlenbach depend both on effective runoff volume and on peak discharge (Rickenmann, 1997; Rickenmann et al., 2012; Turowski, 2012).

Yet, short and intensive, convective-type rainfall events are particularly difficult to accurately predict at the local scale. Flash floods are difficult to observe (Marchi et al., 2010), often because the rainfall estimation at such small spatial and temporal scales is not sufficiently detailed even when using dense rain gauge networks (Anagnostou et al., 2006). Real-time rainfall measurements or precipitation radar data are only of moderate help because of the fast runoff formation observed in many of the small torrential catchments confronted with acute fluvial bedload problems. However, the installation of flashing lights triggered by automated alerts that are issued under certain pluviometric conditions is conceivable to protect, for example, road and railway infrastructure or footpaths. Such organizational measures have been established for debris-flow protection in various Alpine regions (e.g. Bacchini and Zannoni, 2003; Badoux et al., 2009). There, however, lights are activated when a debris flow is detected in the channel (using, for example, geophones or distance measuring devices) and not by means of local rainfall threshold curves.

\subsection{Comparison with threshold lines for other natural hazard processes}

In Fig. 10a we compare a few selected local rainfall intensity-duration threshold lines for the triggering of Alpine debris flows and the onset of fluvial bedload transport. The underlying precipitation data (volume and duration) in all the illustrated cases is recorded until the start of the process. The Illgraben debris-flow threshold line (McArdell and Badoux, 2007) and the bedload threshold lines of the Rio Cordon and Erlenbach display a similar critical rainfall, especially for longer durations of at least a few hours. In contrast, the debris-flow threshold line of the Moscardo torrent in the Italian Alps (located nearby the Rio Cordon) shows a slightly lower negative slope and a considerably higher prefactor $K$ (intercept). The latter point could partly be due to the fact that Deganutti et al. (2000) used hourly rainfall data in their analysis, which results in less accuracy and a slight overestimation of accumulated precipitation. This emphasizes the importance of temporal high resolution data when defining rainfall intensity-duration thresholds for warning purposes, regardless of the natural hazard process.

In studies at the regional or even larger scale with generalized threshold lines, the exact time of process occurrence is often not available or difficult to reconstruct (e.g. Zimmermann et al., 1997). We have compared $I_{\mathrm{T}}-D_{\mathrm{T}}$ threshold lines based on the precipitation recorded for entire events during which debris flows, shallow landslides as well as fluvial bedload transport took place at different spatial scales (Fig. 10b). The $I_{\mathrm{T}}-D_{\mathrm{T}}$ threshold lines for the Erlenbach (bedload transport) and the very active Illgraben (debris flows) plot close to each other, as observed for the $I_{\mathrm{BLS}}-D_{\mathrm{BLS}}$ threshold lines. Lines for local processes (Erlenbach, Illgraben) might be lower than generalized threshold lines due to the availability of more accurate rainfall data. This applies for the case of the threshold line of Zimmermann et al. (1997) based on debris-flow events in Switzerland as well as several nobedload events and threshold-events. Note, however, that a considerable fraction of misses of nearly 0.20 is accepted in this approach whereas the false alarm rate is kept very low (Zimmermann et al., 1997), which means that the threshold 


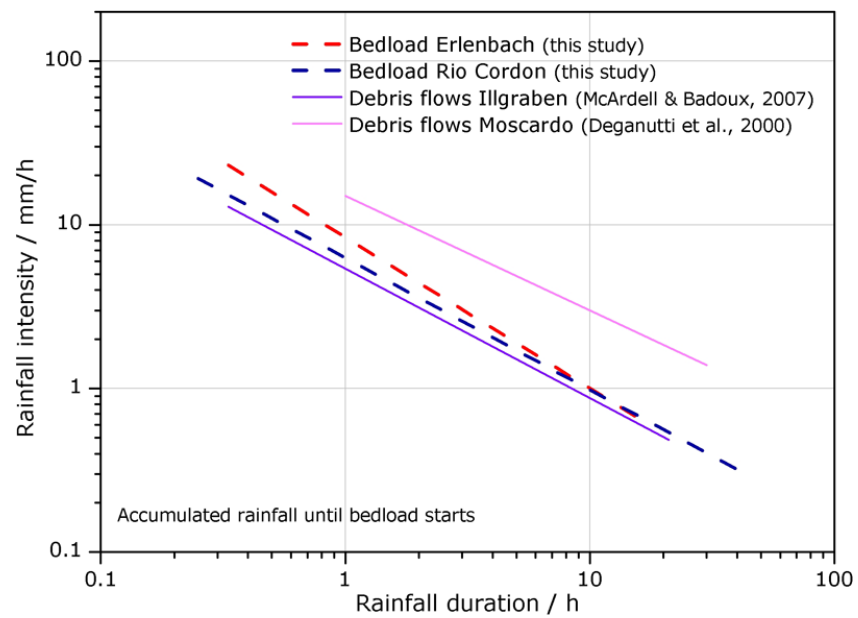

(a)

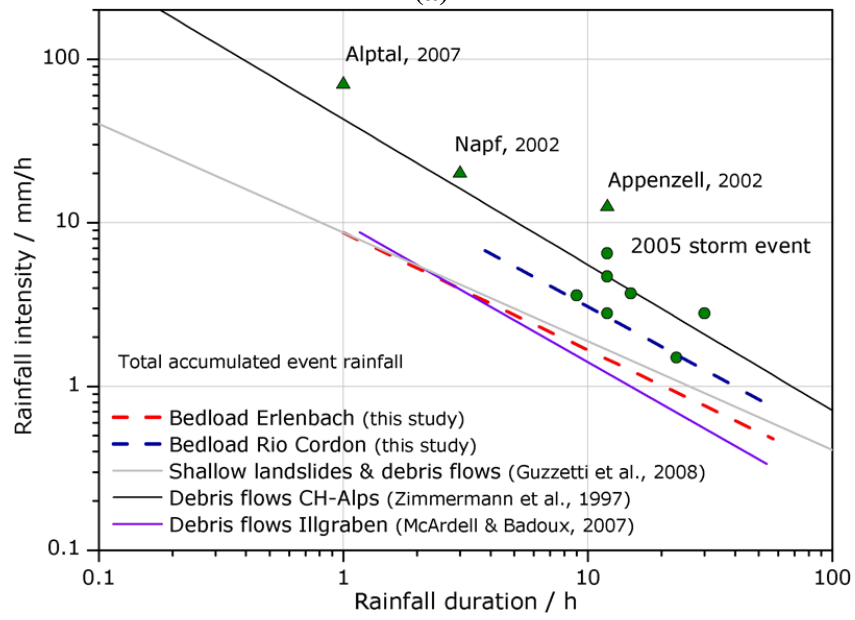

(b)

Fig. 10. Comparison of rainfall intensity-duration relationships for different natural hazard processes: (a) $I_{\mathrm{BLS}}-D_{\mathrm{BLS}}$ relationships for the triggering of debris flows in the Moscardo torrent (Deganutti et al., 2000) and Illgraben torrent (McArdell and Badoux, 2007), as well as for the onset of bedload transport (this study); (b) $I_{\mathrm{T}}-$ $D_{\mathrm{T}}$ relationships for the occurrence of debris flows, shallow landslides and bedload transport at different spatial scales. Triangles show rainfall characteristics of three convective summer storms that each triggered several hillslope debris flows and shallow landslides within a well-defined perimeter in Switzerland. Dots indicate rainfall characteristics during the large 2005 storm event that lead to similar processes in different Swiss regions (Rickli et al., 2008).

line was not delineated as the minimum threshold for the triggering of debris flows. In contrast, the threshold line suggested by Guzzetti et al. (2008) for the likely initiation of shallow landslides and debris flows in the mountain climate region (Fig. 8f in Guzzetti et al., 2008) plots quite low in $I_{\mathrm{T}}-D_{\mathrm{T}}$ space. It has a slightly lower negative exponent than the local thresholds but nearly identical critical rainfall characteristics for short durations of approximately one to five hours.
The single data points displayed in Fig. 10b each aggregate many small shallow landslides that occurred during rainfall events within a restricted perimeter in the Swiss Alps and Prealps. The different convective storms (Alptal 2007, Napf 2002, Appenzell 2002) and the August 2005 long-duration rainfall event that led to enormous damage in Switzerland (Bezzola and Hegg, 2007) can all be described as severe or very severe. This may explain why the data points predominantly plot quite high in $I_{\mathrm{T}}-D_{\mathrm{T}}$ space compared to the rainfall thresholds for the three catchments $(\mathrm{Er}-$ lenbach, Rio Cordon, Illgraben) or the threshold line proposed by Guzzetti et al. (2008) in Fig. 10b.

\section{Conclusions}

We investigated thresholds for fluvial bedload transport activity using rainfall data available at high temporal resolution for five small Alpine catchments within three research sites in Switzerland, Italy and France. A total of 370 rainfall events were identified that led to abundant sediment transport in the catchments located in different geographical and morphological regions. Generally, a fairly limited scatter in rainfall intensity was observed for a given rainfall duration until the onset of bedload transport. Scatter in the duration data for a given mean event intensity is larger. However, for nobedload events (rainfall events not leading to transport) rainfall intensity and duration were found to span over an even larger range. The investigated catchments did not necessarily show identical data distribution. While the entire range of rainfall events (short, medium and long-lasting) lead to bedload activity in the Erlenbach and Vogelbach, transport was observed almost exclusively during floods caused by (very) long-duration precipitation in the Rio Cordon. In the Draix catchments Laval and Moulin, precipitation events longer than $20 \mathrm{~h}$ with low mean intensities $I_{\mathrm{T}}$ of 0.6 to $2.3 \mathrm{~mm} \mathrm{~h}^{-1}$ are overrepresented in comparison with the Alptal catchments and the Rio Cordon. Such events often occur in autumn when material leftover from larger summer storms is still available in the channels and is transported at low discharges.

Intensity-duration threshold lines were defined for the different catchments, above which sediment transport activity has to be expected and below which it was scarcely observed. Although the distribution of rainfall data (until the start of transport) was different in the Rio Cordon compared to the two Alptal catchments, the resulting threshold lines were similar. In three of the five investigated catchments, a break-point was discernible in the intensity-duration data. Beyond this break-point, the threshold for long-duration rainfall events is controlled by rainfall intensity only. This can be expected from simple theoretical considerations. The feature cannot be described by the simple empirical power law threshold line we defined; in fact, the range of rainfall characteristics causing subsequent bedload transport could 
probably better be delimited using three lines: (a) a line of constant minimum duration at very high rainfall intensities, (b) a line of constant minimum intensity for very longduration rainfall events, and (c) a power law threshold line joining the previous two domains.

For the Erlenbach and Rio Cordon catchments, it was possible to determine no-bedload events. Defining the threshold lines in a traditional way, giving a near-zero fraction of misses, we calculated a false alarm rate of 0.67 for the Erlenbach and 0.92 for the Rio Cordon. With a false alarm rate of 0.33 in the Erlenbach for short-duration rainfall events, results are better and somewhat comparable to scores achieved in studies on the triggering of debris flows in Alpine regions. These results suggest that depending on the aim one tries to achieve by setting a threshold line, false alarm ratios should be taken into account. At least for the protection of human life by including automated alerts along transportation infrastructure (e.g. roads, railway), a threshold line defined by a single power law function seems appropriate for prediction purposes in case of short-duration/high-intensity rainfall.

Compared to rainfall threshold lines established for other natural hazard processes such as debris flows, hillslope debris flows or shallow landslides, our threshold lines for the initiation of fluvial sediment transport do not reveal any substantial differences. As for soil instabilities, the threshold values of rainfall intensity-duration relationships strongly depend on the quality and the representativeness of the available rainfall data.

Acknowledgements. The instruments at the Erlenbach hydrological observatory have been designed, built, and maintained with the help of many people over the last 40 years. We especially thank B. Fritschi for continuing technical support and commitment. Thanks are also due to L. Bernhard for support with data handling. The Arabba Avalanche Center (Veneto Region, Italy), in particular G. R. Scussel and W. Testor, is acknowledged for maintaining the Rio Cordon station and providing data. This study was largely funded by the Swiss National Science Foundation (SNSF) projects 200021_124634/1 and 406140-125975/1. We thank C. Tzimopoulos and L. Marchi and editor in chief F. Guzzetti for their constructive comments that helped to improve this paper.

Edited by: F. Guzzetti and N. R. Dalezios

Reviewed by: C. Tzimopoulos and L. Marchi

\section{References}

Anagnostou, E. N., Grecu, M., and Anagnostou, M. N.: X-band polarimetric radar rainfall measurements in keys area microphysics project, J. Atmos. Sci., 63, 187-203, 2006.

Antoine, P., Giraud, A., Meunier, M., and VanAsch, T.: Geological and geotechnical properties of the "Terres Noires" in southeastern France: Weathering, erosion, solid transport and instability, Eng. Geol., 40, 223-234, 1995.

Bacchini, M. and Zannoni, A.: Relations between rainfall and triggering of debris-flow: case study of Cancia (Dolomites,
Northeastern Italy), Nat. Hazards Earth Syst. Sci., 3, 71-79, doi:10.5194/nhess-3-71-2003, 2003.

Badoux, A., Graf, C., Rhyner, J., Kuntner, R., and McArdell, B. W.: A debris-flow alarm system for the Alpine Illgraben catchment: design and performance, Nat. Hazards, 49, 517-539, 2009.

Bathurst, J. C., Graf, W. H., and Cao, H. H.: Bed load discharge equations for steep mountain rivers, in: Sediment Transport in Gravel-bed Rivers, edited by: Thorne, C. R., Bathurst, J. C., and Hey, R. D., 453-477, John Wiley, New York, 1987.

Berti, M. and Simoni, A.: Experimental evidences and numerical modelling of debris flow initiated by channel runoff, Landslides, 2, 171-182, 2005.

Bezzola, G. R. and Hegg, C. (Eds.): Ereignisanalyse Hochwasser 2005, Teil 1 - Prozesse, Schäden und erste Einordnung, UmweltWissen Nr. 0707, Bundesamt für Umwelt BAFU und Eidg. Forschungsanstalt WSL, Bern, 215 pp., 2007.

Blijenberg, H. M.: Rolling Stones? Triggering and frequency of hillsope debris flows in the Bachelard Valley, southern French Alps., University of Utrecht, Utrecht, The Netherlands, 223 pp., 1998.

Brardinoni, F. and Hassan, M. A.: Glacially-induced organization of channel-reach morphology in mountain streams, J. Geophys. Res., 112, F03013, doi:10.1029/2006JF000741, 2007.

Buffington, J. M. and Montgomery, D. R.: A systematic analysis of eight decades of incipient motion studies, with special reference to gravel-bedded rivers, Water Resour. Res., 33, 1993-2029, 1997.

Burch, H., Forster, F., and Schleppi, P.: Zum Einfluss des Waldes auf die Hydrologie der Flysch-Einzugsgebiete des Alptals, Schweizerische Zeitschrift für Forstwesen, 147, 925-938, 1996.

Ceriani, M., Lauzi, S., and Padovan, N.: Rainfalls and landslides in the alpine area of Lombardia region - Central Alps - Italy, in: Interpraevent 1992, 2, 9-20, Bern, 1992.

Chan, R. K. S. and Pun, W. K.: Landslip warning system in Hong Kong, Geotechnical News, 22, 33-34, 2004.

Deganutti, A. M., Marchi, L., and Arattano, M: Rainfall and debrisflow occurrence in the Moscardo basin (Italian Alps), in: DebrisFlow Hazards Mitigation: Mechanics, Prediction, and Assessment, edited by: Wieczorek, G. F. and Naeser, N. D., Balkema, Rotterdam, 67-72, 2000.

Diakakis, M.: Rainfall thresholds for flood triggering, The case of Marathonas in Greece, Nat. Hazards, 60, 789-800, 2012.

Gregoretti, C. and Dalla Fontana, G.: Rainfall threshold for the initiation of debris flows by channel-bed failure in the Dolomites, in: Debris-Flow Hazards Mitigation: Mechanics, Prediction, and Assessment, edited by: Chen, C. L. and Major, J. J., Millpress, Rotterdam, 11-22, 2007.

Gregoretti, C. and Dalla Fontana, G.: The triggering of debris flow due to channel-bed failure in some alpine headwater basins of the Dolomites: analyses of critical runoff, Hydrol. Process., 22, 2248-2263, doi:10.1002/hyp.6821, 2008.

Guzzetti, F., Peruccacci, S., Rossi, M., and Stark, C. P.: The rainfall intensity-duration control of shallow landslides and debris flows: an update, Landslides, 5, 3-17, 2008.

Hegg, C., McArdell, B. W., and Badoux, A.: One hundred years of mountain hydrology in Switzerland by the WSL, Hydrol. Process., 20, 371-376, 2006.

Hilker, N., Badoux, A., and Hegg, C.: The Swiss flood and landslide damage database 1972-2007, Nat. Hazards Earth Syst. Sci., 9, 913-925, doi:10.5194/nhess-9-913-2009, 2009. 
Holub, M. and Hübl, J.: Local protection against mountain hazards - state of the art and future needs, Nat. Hazards Earth Syst. Sci., 8, 81-99, doi:10.5194/nhess-8-81-2008, 2008.

Johnson, K. A. and Sitar, N.: Hydrologic conditions leading to debris-flow initiation, Can. Geotech. J., 27, 789-801, 1990.

Keefer, D. K., Wilson, R. C., Mark, R. K., Brabb, E. E., Brown, W. M., Ellen, S. D., Harp, E. L., Wieczorek, G. F., Alger, C. S., and Zatkin, R. S.: Real-Time Landslide Warning During Heavy Rainfall, Science, 238, 921-925, 1987.

Lenzi, M. A.: Step-pool evolution in the Rio Cordon, northeastern Italy, Earth Surf. Proc. Landf., 26, 991-1008, 2001.

Lenzi, M. A., D'Agostino, V., and Billi, P.: Bedload transport in the instrumented catchment of the Rio Cordon: Part I: Analysis of bedload records, conditions and threshold of bedload entrainment, Catena, 36, 171-190, 1999.

Lenzi, M. A., Mao, L., and Comiti, F.: Magnitude-frequency analysis of bed load data in an Alpine boulder bed stream, Water Resour. Res, 40, W07201, doi:10.1029/2003WR002961, 2004.

Lenzi, M. A., Mao, L., and Comiti, F.: Effective discharge for sediment transport in a mountain river: Computational approaches and geomorphic effectiveness, J. Hydrol., 326, 257-276, 2006.

Mao, L., Uyttendaele, G. P., Iroumé, A., and Lenzi, M. A.: Field based analysis of sediment entrainment in two high gradient streams located in Alpine and Andine environments, Geomorphology, 93, 368-383, 2008.

Mao, L., Cavalli, M., Comiti, F., Marchi, L., Lenzi, M. A., and Arattano, M.: Sediment transfer processes in two Alpine catchments of contrasting morphological settings, J. Hydrol., 364, 88-98, 2009.

Mao, L., Comiti, F., and Lenzi, M. A.: Bedload Dynamics in Steep Mountain Rivers: Insights from the Rio Cordon Experimental Station (Italian Alps), in: Bedload-surrogate monitoring technologies, edited by: Gray, J. R., Laronne, J. B., and Marr, J. D. G., 253-265, 2010.

Marchi, L., Borga, M., Preciso, E., and Gaume, E.: Characterisation of selected extreme flash floods in Europe and implications for flood risk management, J. Hydrol., 394, 118-133, 2010.

Mathys, N.: Analyse et modélisation à différentes échelles des mécanismes d'érosion et de transport de matériaux solides, Cas des petits bassins versants de montagne sur marne (Draix, Alpesde-Haute-Provence), PhD thesis, Grenoble Institute of Technology, Grenoble, France, 341 pp., 2006.

Mathys, N., Brochot, S., Meunier, M., and Richard, D.: Erosion quantification in the small marly experimental catchments of Draix (Alpes de Haute Provance, France), Calibration of the ETC rainfall-runoff-erosion model, Catena, 50, 527-548, 2003.

Mathys, N., Klotz, S., Esteves, M., Descroix, L., and Lapetite, J. M.: Runoff and erosion in the Black Marls of the French Alps: Observations and measurements at the plot scale, Catena, 63, 261-281, 2005.

Mathys, N., Esteves, M., and Gresillon, J. M.: The seasonal cycle of deposition and scouring in the channel network as a key process for erosion response in badlands catchments, (Draix, Alpes-deHaute-Provence, France), Geophys. Res. Abstr., 9, 08654, SRefID: 1607-7962/gra/EGU2007-A-08654, EGU General Assembly 2007, Vienna, Austria, 2007.

McArdell, B. W. and Badoux, A.: Influence of rainfall on the initiation of debris flows at the Illgraben catchment, canton of Valais, Switzerland, Geophys. Res. Abstr., 9, 08804, SRef-ID: 1607-
7962/gra/EGU2007-A-08804, EGU General Assembly 2007, Vienna, Austria, 2007.

Nitsche, M., Rickenmann, D., Turowski, J. M., Badoux, A., and Kirchner, J. W.: Evaluation of bedload transport predictions using flow resistance equations to account for macro-roughness in steep mountain streams, Water Resour. Res., 47, W08513, doi:10.1029/2011WR010645, 2011.

Rickenmann, D.: Bedload transport capacity of slurry flows at steep slopes. Mitteilungen der Versuchsanstalt für Wasserbau, Hydrologie und Glaziologie Nr. 103, Eidgenössische Technische Hochschule Zürich, Zurich, Switzerland, 1990.

Rickenmann, D.: Sediment transport in Swiss torrents, Earth Surf. Proc. Landf., 22, 937-951, 1997.

Rickenmann, D. and Fritschi, B.: Bedload transport measurements using piezoelectric impact sensors and geophones, in: Bedload-surrogate Monitoring Technologies, edited by: Gray, J. R., Laronne, J. B., and Marr, J. D. G., US Geological Survey Scientific Investigations Report 2010-5091, US Geological Survey, Reston, VA, 407-423, available at: http://pubs.usgs.gov/sir/2010/ 5091/papers/listofpapers.html (last access: 30 July 2012), 2010.

Rickenmann, D. and Koschni, A.: Sediment loads due to fluvial transport and debris flows during the 2005 flood events in Switzerland, Hydrol. Process., 24, 993-1007, 2010.

Rickenmann, D. and McArdell, B. W.: Continuous measurement of sediment transport in the Erlenbach stream using piezoelectric bedload impact sensors, Earth Surf. Proc. Landf., 32, 1362-1378, 2007.

Rickenmann, D. and McArdell, B. W.: Calibration of piezoelectric bedload impact sensors in the Pitzbach mountain stream, Geodin. Acta, 21, 35-52, 2008.

Rickenmann, D., Turowski, J. M., Fritschi, B., Klaiber, A., and Ludwig, A.: Bedload transport measurements at the Erlenbach stream with geophones and automated basket samplers, Earth Surf. Proc. Landf., 37, 1000-1011, doi:10.1002/esp.3225, 2012.

Rickli, C., Raetzo, H., McArdell, B. W., and Presler, J.: Hanginstabilitäten, in: Ereignisanalyse Hochwasser 2005, Teil 2 Analyse von Prozessen, Massnahmen und Gefahrengrundlagen, edited by: Bezzola, G. R. and Hegg, C., 97-116, UmweltWissen Nr. 2508, Bundesamt für Umwelt BAFU und Eidg. Forschungsanstalt WSL, Bern, 2008.

Turowski, J. M.: Discussion of "Can we link cause and effect in landscape evolution" by T. Coulthard and M. Van De Wiel, in: Gravel Bed Rivers: Processes, tools, environments, edited by: Church, M., Biron, P., and Roy, A., John Wiley and Sons, Chichester, 518-520, 2012.

Turowski, J. M. and Rickenmann, D.: Tools and cover effects in bedload transport observations in the Pitzbach, Austria, Earth Surf. Proc. Landf., 34, 26-37, doi:10.1002/esp.1686, 2009.

Turowski, J. M., Yager, E. M., Badoux, A., Rickenmann, D., and Molnar, P.: The impact of exceptional events on erosion, bedload transport and channel stability in a step-pool channel, Earth Surf. Proc. Landf., 34, 1661-1673, doi:10.1002/esp.1855, 2009.

Turowski, J. M., Badoux, A., and Rickenmann, D.: Start and end of bedload transport in gravel-bed streams, Geophys. Res. Lett., 38, L04401, doi:10.1029/2010GL046558, 2011.

Zimmermann, M., Mani, P., Gamma, P., Gsteiger, P., Heiniger, O., and Hunziker, G.: Murganggefahr und Klimaänderung - ein GISbasierter Ansatz (Schlussbericht NFP31), vdf Hochschulverlag, Zurich, Switzerland, 1997. 